\title{
WestVirginiaUniversity
}

THE RESEARCH REPOSITORY @ WVU

Graduate Theses, Dissertations, and Problem Reports

2006

\section{Optimal bucking hardwood species in Central Appalachia}

Jingang Liu

West Virginia University

Follow this and additional works at: https://researchrepository.wvu.edu/etd

\section{Recommended Citation}

Liu, Jingang, "Optimal bucking hardwood species in Central Appalachia" (2006). Graduate Theses, Dissertations, and Problem Reports. 2392.

https://researchrepository.wvu.edu/etd/2392

This Thesis is protected by copyright and/or related rights. It has been brought to you by the The Research Repository @ WVU with permission from the rights-holder(s). You are free to use this Thesis in any way that is permitted by the copyright and related rights legislation that applies to your use. For other uses you must obtain permission from the rights-holder(s) directly, unless additional rights are indicated by a Creative Commons license in the record and/ or on the work itself. This Thesis has been accepted for inclusion in WVU Graduate Theses, Dissertations, and Problem Reports collection by an authorized administrator of The Research Repository @ WVU. For more information, please contact researchrepository@mail.wvu.edu. 


\title{
Optimal Bucking Hardwood Species in Central Appalachia
}

\author{
Jingang Liu \\ Thesis submitted to the \\ Davis College of Agriculture, Forestry and Consumer Sciences \\ at West Virginia University \\ in partial fulfillment of the requirements \\ for the degree of \\ Master of Science \\ in \\ Forest Resources Science \\ Jingxin Wang, Ph. D., Committee Chair \\ Joe McNeel, Ph. D. \\ John Brooks, Ph. D.
}

Division of Forestry and Natural Resources

Morgantown, West Virginia

2006

Keywords: Optimal bucking, network analysis, 3D modeling, OpenGL, relational data model, Appalachian hardwoods. 


\section{ABSTRACT \\ Optimal Bucking Hardwood Species in Central Appalachia}

\section{Jingang Liu}

An optimal tree-stem bucking system was developed for central Appalachian hardwood species using 3D modeling techniques. ActiveX Data Objects were implemented via MS Visual C++/OpenGL to manipulate tree data which were supported by a backend relational data model with five data tables for stems, grades and prices, logs, defects and stem shapes. Network analysis was employed to achieve the optimal bucking solution with four different alternative stage intervals under bucking by value principle. Once all the data associated with a tree were retrieved, a 3-D tree stem could be displayed for either optimal or manual bucking based on the user's option. Doyle and International $1 / 8$ " log rules were used to compute the log volumes during the bucking processes. Compared to manual bucking, total log value and volume gain from each tree-stem by using this computer bucking system could be increased averagely by $31.39 \%$ to $37.69 \%$ and $16.03 \%$ to $16.60 \%$. Also, by computer optimal bucking, tree-stem utilization rate was increased by $10.11 \%$ to $11.23 \%$ compared to manual bucking results. The system execution time increased by 13, 108, and 1702 times while bucking stage interval changed from 4-foot, to 1-foot, 4-inch, and 1-inch. The optimal bucking system developed can be used as a training tool on desktop PCs and can also be installed on field PCs to aid field buckers. 


\section{DEDICATIONS}

I would like to dedicate this thesis to my wife, Yu Jing, my sister, my brother, and my parents for their endless love and unselfish support throughout my life and career. 


\section{ACKNOWLEDGEMENTS}

I would like to give special gratitude to my major professor, Dr. Jingxin Wang, for his perspective suggestions, patience, and inspiration throughout my graduate study. Deep gratitude and appreciation also goes to my advisory committee members: Dr. Joseph McNeel and Dr. John Brooks for their consistent support and guidance.

I would like to thank Mr. Tony Goff for his help during the field work. Also I am grateful to my officemates: Mr. Nathan Beane, Mr. Benktesh Sharma, Mr. Greg Hamons, Mr. William Sharp and Mrs. Lisa Freeman. It is really great fun to work with you guys. 


\section{TABLE OF CONTENTS}

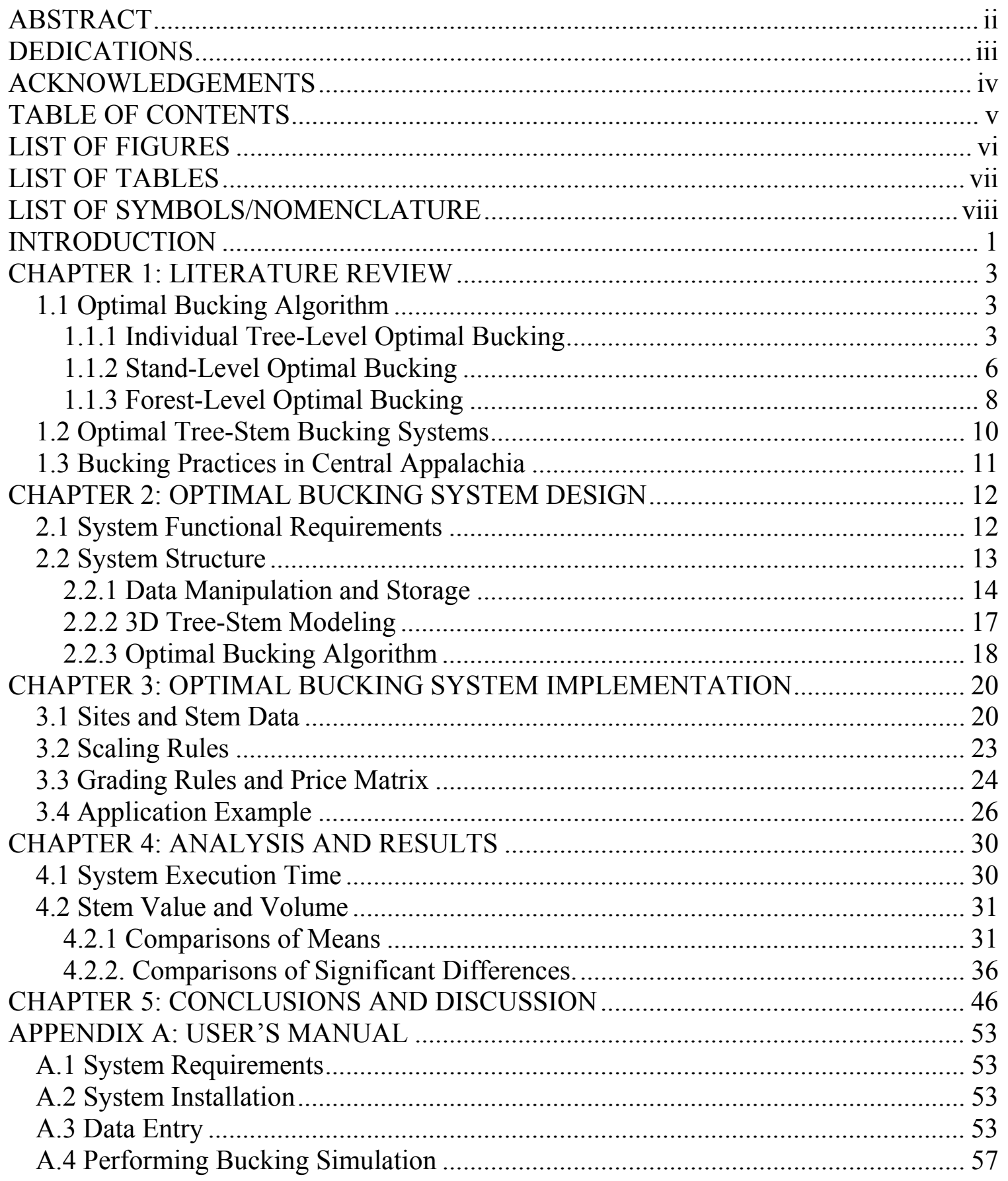




\section{LIST OF FIGURES}

Figure 2.1. Flow chart of optimal bucking system. ............................................... 14

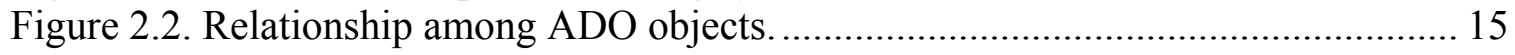

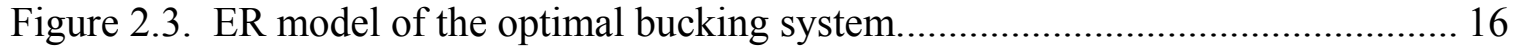

Figure 3.1. Relationships between tree-stem, defects, shapes and grades..................... 26

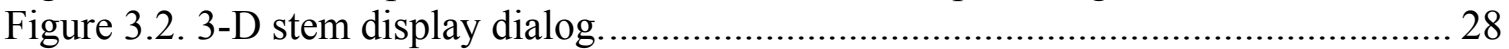

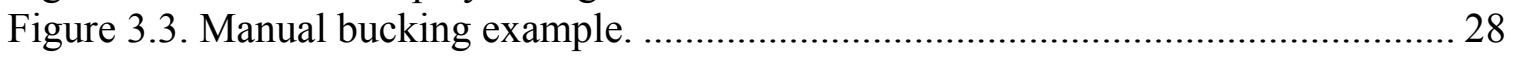

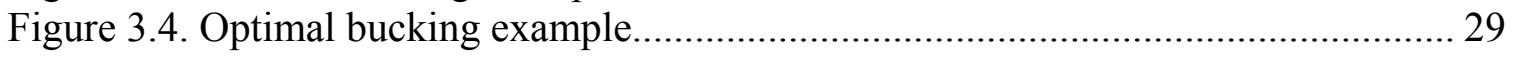

Figure 4.1. System execution time vs. stage interval of optimal bucking. ...................... 30

Figure 4.2. Average stem value, volume and value/BF increase by optimal bucking...... 33

Figure 4.3. Increase of value per stem vs. stage interval by DBH class.......................... 34

Figure 4.4. Increase of value per stem vs. stage interval by MHT class. ........................ 35

Figure 4.5. Increase of value per stem vs. stage interval by species............................. 35

Figure 4.6. Increase of value pre stem vs. stage interval by bucker's experience........... 36

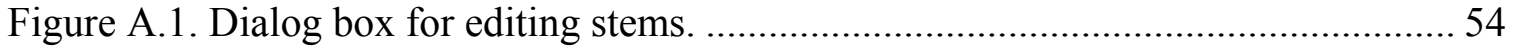

Figure A.2. Dialog box for editing stem shapes. .................................................... 55

Figure A.3. Dialog box for editing stem defects........................................................ 56

Figure A.4. Dialog box for editing log grades and prices........................................ 57

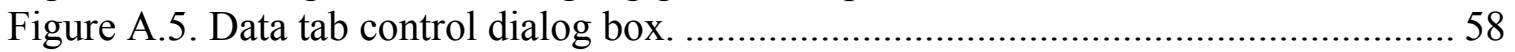

Figure A.6. A 3-D tree-stem for bucking simulation................................................ 58 


\section{LIST OF TABLES}

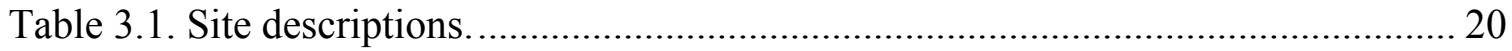

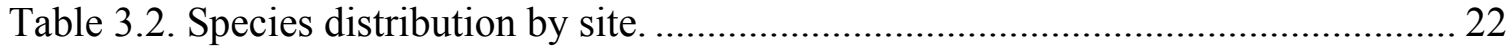

Table 3.3. DBH and MHT statistics by site.............................................................. 22

Table 3.4. DBH and MHT statistics by species.......................................................... 22

Table 3.5. DBH and MHT class distribution by species............................................. 22

Table 3.6. Average number and size of defects statistics by species.............................. 23

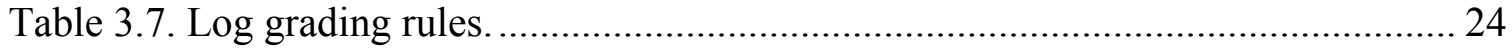

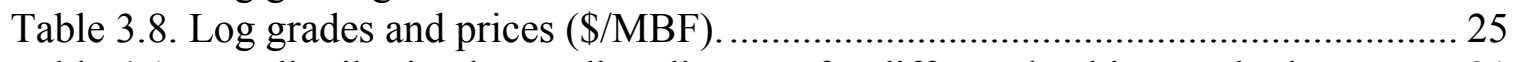

Table 4.1. Log distribution by grading diameter for different bucking methods. ............ 31

Table 4.2. Log distribution by grading length for different bucking methods. ............... 32

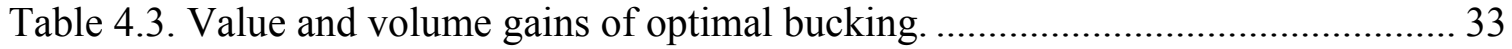

Table 4.4. One tailed t-test for optimal bucking vs. manual bucking results. ................. 37

Table 4.5. Means and significance levels of bucking results by manual bucking........... 39

Table 4.6. Means and significance levels of bucking results by optimal bucking........... 42

Table 4.7. Means and significance levels of generic bucking results............................ 44

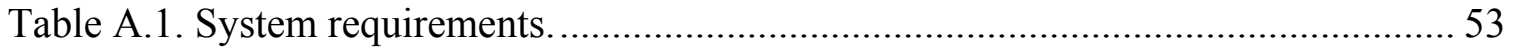

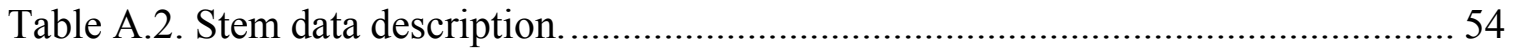

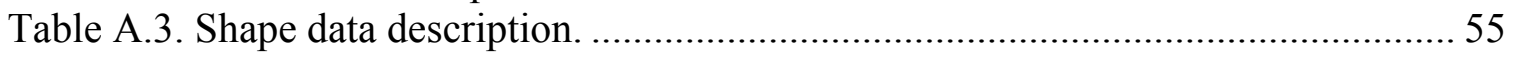

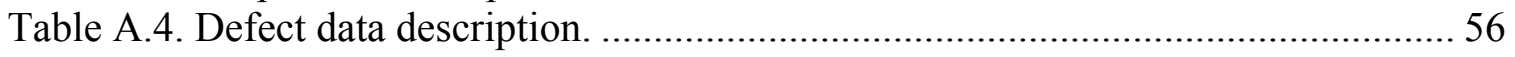

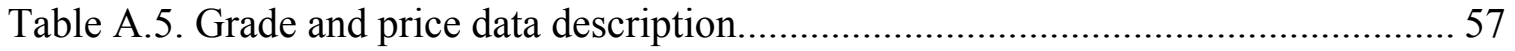




\section{LIST OF SYMBOLS/NOMENCLATURE}

$\begin{array}{ll}Y P & \text { Yellow-poplar } \\ R O & \text { Red oak } \\ \text { WO } & \text { White oak } \\ C O & \text { Chestnut oak } \\ \text { BO } & \text { Black oak } \\ \text { SO } & \text { Scarlet oak } \\ B D & \text { Bark distortion } \\ B U & \text { Bugle } \\ S P & \text { Split } \\ S T & \text { Stain } \\ H O & \text { Hole } \\ D P & \text { Dynamic programming } \\ L P & \text { Linear programming } \\ T S & \text { Tabu search } \\ D B H & \text { Diameter at breast height } \\ B F & \text { Board feet } \\ M H T & \text { Tree merchantable height } \\ T H T & \text { Tree total height } \\ G L M & \text { General linear model } \\ \text { SAS } & \text { Statistical analysis system }\end{array}$




\section{INTRODUCTION}

Tree bucking is the activity of cutting a stem into logs suitable for further processing such as sawlogs, pulp logs, poles, and other similar products (Eng et al. 1986). It is also the first step for converting tree stems into lumber and other forest products (Näsberg 1986). Since the processing of logs is in part dependent on cutting decisions, potential profits can be lost if a tree is bucked into logs without fully considering the multitude of end-uses and market constrains.

Tree stem bucking is also a complex problem because the decision of where to cut dependents on various factors including species of the stem, grades of logs within the stem length and market value for end products, diameter, number, location and severity of defects, and taper rate (Bobrowski 1994a). The process of producing logs from tree stems attaining the highest value, demonstrated bucking optimization problem (Pickens et al. 1997). During the last half century, scientists all over the world have paid particular attention to the optimal bucking problem because it is not only one of the most efficient ways to increase profits for forest enterprises, but is also considered as a way to more fully utilize forest resources. Previous studies reported that the average manual log bucking practice typically reduced the potential value obtainable from a tree by $20 \%$ compared to what was considered to be good practice (Faaland and Briggs 1984). Studies of softwood bucking practices in New Zealand and the Pacific Northwest have revealed gross value losses ranging from 5-26\% (Geerts and Twaddle 1985, Sessions et al. 1989a, Twaddle and Goulding 1989). A study of 166 northern hardwood trees in Michigan indicated that the gross delivered value of optimal solutions were 39 to $55 \%$ higher than those chosen by buckers (Pickens et al. 1992). Optimal bucking also 
demonstrated a 12 percent of value increase per cubic meter for bucking the northeastern species in China (Wang and Xu 1990, Wang et al. 2004).

With the need for the forest industry to use raw material much more efficiently, the potential benefit from improving bucking for high quality logs appears essential. The bucking practices in central Appalachian region demonstrated the need of a bucking aid tool for training and filed applications. Therefore, the objectives of this study are to (1) develop an optimal tree-stem bucking system for central Appalachian hardwood species with 3-D visual simulation environment; (2) investigate the hardwood log bucking practice in the field, and (3) statistically compare manual bucking and optimal bucking in terms of log volume and value gain. 


\section{CHAPTER 1: LITERATURE REVIEW}

During the last 6 decades, optimal bucking has been extensively studied on different levels with different algorithms (Pnevmaticos and Mann 1972, Lawrence 1986, Sessions 1988, Wang et al. 2004). Mathematical programming techniques including linear programming, dynamic programming, and network analysis have been used to solve optimal bucking problems. These techniques can be applied separately or linked together in solving optimal bucking problem. In recent years, some heuristic approaches like Tabu search (Laroze and Greber 1997, Laroze 1999), genetic algorithm approach (Kivinen 2004) and fuzzy logic (Kivinen and Uusitalo 2002) also were explored to solve optimal bucking problems.

\subsection{Optimal Bucking Algorithm}

\subsubsection{Individual Tree-Level Optimal Bucking}

At the individual tree-level, the problem is to determine bucking patterns that maximize tree value under given log grading rules, price matrix and production limitations (Laroze 1999). Individual tree optimal bucking models are used as the fundamental of more complex bucking problems at the stand or forest level while considering market and resource constrains.

Forster and Callahan (1968) modeled the individual tree bucking problem as a linear programming model (Näsberg 1985). The objective was presented as the sum of stem conversion surplus value times the number of units of a particular log produced from a particular portion of the stem. Faaland and Briggs (1984) further developed the model as an integer knapsack problem. 
The limitations of these approaches are the usual limitation with linear programming. It is assumed that all relationships in the model are linear. However, it may be that the costs and returns for bucking are not linear (Wang et al. 2004). Further, each solution of the linear programming model gives an optimal solution under only one set of specified conditions. In the general bucking problem, the optimal bucking policy may not be the best solution of linear programming. In linear programming, all constraints are in the same importance level, they should be not in the same important level in practical bucking (Wang et al. 2004). Another big problem for their model was that only a number of most commonly used bucking patterns were applied in this model, which may not obtain the optimal solution.

The principle of dynamic programming (DP) is, as stated by Bellmon and Dreyfus (1962) "an optimal policy has the property that whatever the initial state and initial decisions are, the remaining decisions must constitute an optimal policy with regard to the state resulting from the previous action” or as stated by Aris (1964) “...if you don't do the best you can with what you happen to have got, you'll never do the best you might have done with what you should have had." The first attempt at formulating and predicting individual tree optimal bucking problem using a DP routine was proposed by Clemmons (1966). Although this model was a valuable conceptual step, it has limited practical use because it assumes uniform taper with log grades based on probabilities (Pickens et al. 1992). The first detailed DP algorithm for obtaining the optimal bucking pattern for an individual tree was developed by Pnevmaticos and Mann (1972). In this model, the stem is considered to be made up of a sequence of stage, each stage represents an individual minimum length of log, and then the bucking problem could be viewed as a 
sequential decision process. This process contains as many stages as there are minimum length of logs. Thus, at each decision point one must decide whether or not to make a cut. At each stage, an optimal solution from all previous stages, under any conditions, is found and carried into the next stage. At last stage the optimal policy is achieved for the whole stem. Dynamic programming has been proved to be the most popularly used techniques for solving optimal bucking problems. Several similar DP models have been developed (Briggs 1980, Eng 1982, Eng and Daellenbach 1985, Geerts and Twaddle 1985, Faaland and Briggs 1984) after Pnevmaticos and Mann's model. In contrast to linear programming, the formulation of dynamic programming problems is generally more difficult. A standard algorithm like the simplex method does not exist (Wang et al. 2004).

Network analysis techniques have been introduced into individual tree optimal bucking process since the mid-1980s (Näsburg 1985, Sessions 1988, Sessions et al. 1989b). Wang et al. (2004) developed a computer-based bucking model for northeastern tree species of China using the labeling algorithm of network analysis. The network analysis divides the stem into a sequence of nodes, which represent the possible cutting positions. There are three basic steps when using network analysis algorithm to solve the optimal bucking problem: (1) analyze the bucking cost and price of logs; (2) generate the network including the nodes, arcs and arc values; (3) determine the longest path in the network, that is, the maximum value path for a tree-stem (Wang et al. 2004).

Bobrowski (1990, 1994a and 1994b) introduced a branch-and-bound method for optimal bucking and compared its solutions with dynamic programming strategies. The branch-and-bound procedure consists of creating a node network interconnected by arcs. 
Each node emanates a maximum of $n+1$ arcs (in the pre-specified number of logs plus the possibility of cutting a log with length less than the shortest pre-specified length to remove all or part of a defect). Arcs represent the possible log candidates as a tree is bucked from the large end to the small end diameter. The node at the end of each arc represents a series of candidate cuts for the stem by tracing backwards from the current node to the root node, as well as the value of those candidate cuts plus an estimate of the value of the unbucked portion of the stem. Bobrowski (1990, 1994a and 1994b) reported that branch-and-bound and dynamic programming generated the same solutions for log bucking problem only for the simplest scenarios. If a stem has more defects, the DP algorithm needs to engage a shorter stage to yield the same accuracy solution as the branch-and-bound method.

\subsubsection{Stand-Level Optimal Bucking}

Under open market conditions that the quantity of logs have no effects on log prices, the stand-level optimal bucking problem might be simply considered as the aggregation of individual tree stem values obtained by using certain optimal bucking methods (Arce et al. 2002). However, when market conditions changed, forest managers must direct the wood resource to meet end users' demands or contractual restrains. Then the optimal bucking problem is to assign bucking patterns to each tree stem class in order to maximize the value of the aggregate production, given the merchandising restrictions imposed by different markets and characteristics of each stand (Laroze 1999).

Smith and Harrell (1961) first used linear programming models to determine the number of trees of each size to be cut into logs of a desired size. In their linear programming model, the cost was based on a two-man crew using a one-man chain saw 
and an axe of bucking tree with different dimensional classes. The model assumed that there were a fixed number of known alternatives for bucking a tree-stem of a specific size into logs. Given those alternatives and their associated profits, and resource and market limitations, the objective was to determine the number of trees of each size to be bucked into logs of a desired size. However, there are some problems in their model. First, only 18 cutting policies were employed in their model. Second, the assumption of no defects was unrealistic and a taper factor was not considered in the model.

The most commonly used approach to stand level optimization is the use of a twostage hierarchical model (Mendoza and Bare 1986, Eng et al. 1986, Sessions et al. 1989b). The first stage decision problem (main problem) is a wood resource allocation model which includes log allocation and the production and sale of finished products. The second stage decision problem (sub-problem) is to generate the optimal bucking policies for each tree stem class (Mendoza and Bare 1986).

Dantzig-Wolfe Decomposition and a DP column generation method were introduced in determining a set of bucking policies that were consistent with the characteristics of both the wood resource and user's market demands (Eng and Daellenbach 1985). This method first used a DP algorithm to find the optimal bucking solution without considering market constrains. At the optimal solution, the internal penalty for scarce resources and the internal premium for end user products in tight supply were assessed. These correspond to the shadow prices of demand and supply constraints, separately. Combining the original product prices with the penalty and premium, a new bucking policy could be generated and the procedure would be terminated when the newly generated bucking policy was not profitable to all tree classes. 
Trees are grouped together by characteristics that are important to the producer, like DBH, species. The solution can be provided in terms of the percentage of a given class of trees to be cut based on a pre-defined pattern. This approach is not appropriate for the demand constrained hardwood log bucking problem because of the difficulty of designing a tree classification system for hardwoods (Pickens et al. 1997).

Sessions et al. (1989b) also used a two-stage model to solve the stand level optimal bucking problem. First, a set of sample trees to be harvested need to be described. An optimal bucking pattern is generated for each tree based on the unadjusted set of log prices. The results are summarized over all trees in the sample set. If the percentage of long-logs satisfies the constraints, log prices are not adjusted for these logs. If the longlog percentage must be increased, the prices for all long logs are increased by a multiplication factor determined through the binary search. The objective of this model is to develop a set of adjusted prices to guide individual tree optimization rather than to derive a set of bucking patterns and then to apply them to individual trees.

\subsubsection{Forest-Level Optimal Bucking}

Forest-level optimal bucking is essentially a whole stand management optimization. This problem occurs when answering to the question "which products in what quantities may be cut from each stand" (Arce et al. 2002). It divides the bucking program into assigning stands and maximizing global profits subject to the demand constraints and merchandising restrictions of different markets, log characteristics, and size of available stands.

Arce et al. (2002) evaluated three scenarios: an observed medium-term forest harvesting, with 32 stands harvested during one month, a simulated demand-oriented, and 
a simulated supply-oriented. Two modules, a cutting pattern generation (CPG), and a global bucking optimization (GBO), were included in the system. In the demand-oriented scenario, the CPG exhaustively generates all possible cutting patterns using an algorithm developed by Laroze and Greber (1997) and the branch and bound algorithm developed by Epstein et al. (1999). The GBO, formulated as mixed integer linear programming problem, optimizes the net revenue at forest level subject to constraints that consider bounds for timber volumes and maximum number of different multi-products obtained in each stand. In the supply-oriented scenario, the CPG generates the optimum cutting pattern through a heuristic algorithm that identifies the potential cutting points along the stem. The DP-based algorithm was used to determine the optimal combination of products that maximizes the stem profit. The GBO calculates the net profit, summarizes the profits per stem for each stand and all stands. The comparisons among these three scenarios showed a $9.08 \%$ and $29.39 \%$ volume increment, and a $9.15 \%$ and $34.12 \%$ profit increment for demand-oriented and supply oriented scenario over observed scenario (Arce et al. 2002).

Laroze (1999) used a tabu search method (LP/TS) to solve bucking optimization at both the stand and forest levels. He compared the results obtained using this approach with different estates, prices, and demand conditions with the solutions obtained by the LP/DP procedure. He found that LP/TS method can consistently achieve an efficient level of approximately $97 \%$ compared to the solutions obtained by LP/DP method (Laroze 1999).

The common assumption in forest-level optimal bucking models is that all of the trees in a stem class are bucked the same way, so only relatively simple market 
constraints and homogeneous stands problem can be solved validly. This assumption ignores the variations of individual tree quality and tree species, so the solution can only provide strategically references to forest managers. Practical implementation is difficult to be done by buckers when they make bucking decisions on site (Pickens et al. 1997).

\subsection{Optimal Tree-Stem Bucking Systems}

Several optimal bucking systems have been developed during last six decades in the U.S.A, Europe, New Zealand and other countries. Experimental applications of these systems showed great value increase can be obtained. Also, there are great potential benefits of using them as training tools to help buckers to enhance their bucking decision making abilities.

A VISION decision simulator was developed to apply dynamic programming in tree-stem bucking at Weyerhaeuser Company (Lembershy and Chi 1984, 1986). Field buckers could develop their bucking decision skills using VISION. The optimal decisions generated by VISION could be used later as new bucking instructions.

Using dynamic programming in New Zealand, Geerts and Twaddle (1985) developed AVIS to maximize a single tree-stem value. Two mechanized bucking operations in the southeastern United States were compared with the optimal values computed using AVIS (Boston and Murphy 2003). They found a 6\% log value loss in final harvesting and a $42 \% \log$ value loss for a thinning operation.

BUCK, developed at Oregon State University (Sessions 1988), is an interactive tree optimizer using network analysis that considered alternative mill prices, transport distances and equipment capability. Garland et al. (1989) compared value recovery from manual log bucking and from using BUCK on a HP handheld computer. They reported a 
$14.2 \%$ and $11.9 \%$ total $\log$ value increases could be achieved when bucking old-growth and second-growth trees using BUCK. BUCK has also been tested on a mechanized harvester, which reported a recovery of 7.5\% for the total value (Olsen et al. 1991).

HW-BUCK was developed by Pickens et al. (1992) for optimal bucking of northern hardwood species, which was designed to help trainees develop heuristics to select the bucking pattern for an individual tree-stem (Frayer et al. 1995). A database containing actual shape information of 150 northern hardwood trees is specifically used for training buckers. Buckers could make their bucking decisions based on a 2-D treestem and compared their decisions with the computer-generated patterns.

\subsection{Bucking Practices in Central Appalachia}

In central Appalachia, difficult terrain and hardwood species make harvesting and bucking more difficult. Ground-based harvesting is still the dominant system. Bucking with a chainsaw or a sawbuck at a landing is the typical practice in this region (Milauskas and Wang 2006, Wang et al. 2006). Most of the loggers are not well trained for bucking and they make their bucking decisions based purely on their past experiences. Hardwood species usually have more defects and sweep than softwoods and their value varies

greatly by species, grade, and dimensions. Based on a log price survey in this region, log values can vary up to $50 \%$, even for the same grade with different length and diameter combinations. For different sawmills, the grading rules and log prices are also different. All these factors make bucking with hardwood species more difficult than bucking softwood species. 


\section{CHAPTER 2: OPTIMAL BUCKING SYSTEM DESIGN}

\subsection{System Functional Requirements}

Based on collected field data of stem shapes and defect information, this optimal bucking system was aimed to provide users with a convenient way to perform bucking optimization, which will maximize the value of the bucked stem under a given grading rule and corresponding price matrix. Also this optimal bucking system would allow users to perform bucking based on their decisions. In either case, the system will display a stem before and after bucking with 3-D image. To fulfill the above mentioned requirements, the optimal bucking system needs to access a database to retrieve shape, defects and grade data. Also, the optimal bucking system needs to be able to calculate the volume and value for any given log or stem based on the given market information. Therefore, the functional requirements of this 3-D optimal bucking system are:

- Data acquisition

- Data standardization

- Value calculation

- Bucking optimization

- 3-D environmental normalization

- 3-D image display

- 3-D image manipulation

- Data storage and analysis

Through GUI interfaces, users are asked to perform a series of pre-set actions

(Figure 2.1). The functional requirements of this 3-D bucking system include:

Editstems(): to add, delete or edit stem shapes collected from the field; 
Editdefects(): to add, delete or edit defects associated with each stem;

Editgrades(): to add, delete or edit log grading rules and set corresponding price matrixes for bucking;

Grade(): to return the grade level of stem or log using a selected grading rule;

Volume(): to calculate stem or log volume using a selected scaling rule;

Value(): to return the total value of a stem or a $\log$ after the grade and volume of the stem or log have been computed;

Optimalbucking(): to perform bucking optimization to achieve the maximum value gain for a selected stem;

Save(): to save bucking results to database;

OpenGLsetup(): to set up the system environment for Open Graphics Library (OpenGL);

Display(): to draw 3-D image of a selected stem or logs with OpenGL;

\subsection{System Structure}

The optimal bucking system consists of four major components: tree stem data manipulation, 3-D modeling, bucking optimization, and data storage (Figure 2.1). Component object model (COM) was employed to integrate the system that was designed using the principle of object-oriented programming (OOP). The system was programmed with Microsoft Foundation Class (MFC) and Open Graphics Library (OpenGL). MFC provides a user friendly interface and can be easily transplanted to any other Windows applications while OpenGL offers great power to create the 3-D virtual bucking environment. The 3-D objects created can be rotated, scaled, and transformed by performing OpenGL transformation. MFC integrated development environment (IDE) 
provides facilities for managing every stage of our program, from creating source code, to building (compiling and linking) the code, to testing, debugging, and optimizing the code (Sphar 1999). With MFC, users can easily build a Windows compatible GUI interface. Through MFC and ActiveX controls, we can link our system database conveniently.

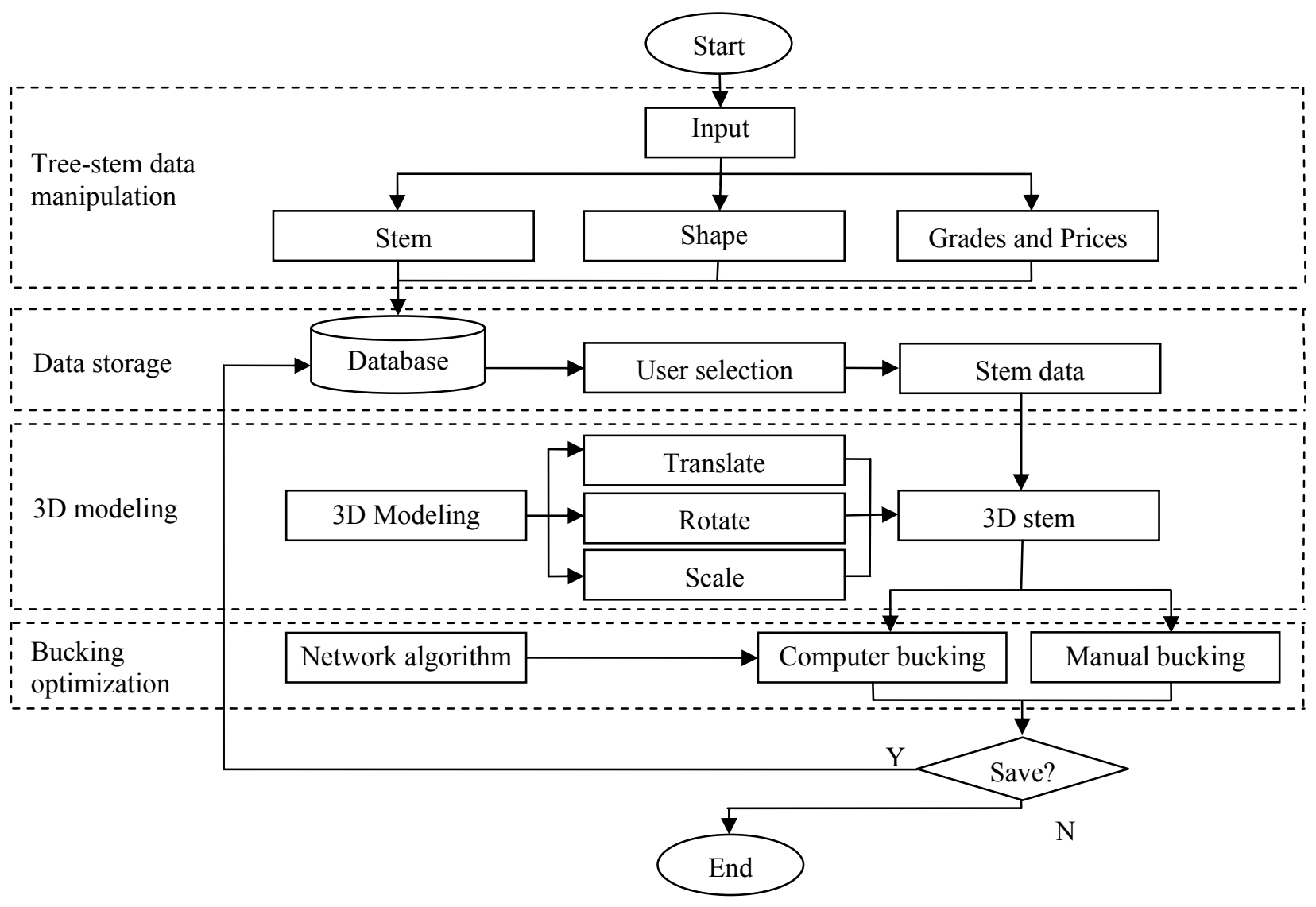

Figure 2.1. Flow chart of optimal bucking system.

\subsubsection{Data Manipulation and Storage}

Active Data Object (ADO) was employed to retrieve data from and save bucking results to an Access database. Compared with other database access methods, ADO provides a user-oriented method of data access (Sarrett 1998). It is a layer inserted between OLE DB and the client, which enables indirect access to the OLE DB provider. This layer helps programmers to easily use OLE DB without knowing the complexity 
behind the $\mathrm{C}++$ class templates. ADO consists of seven basic objects: Connection, Recordset, Command, Error, Field, Property, and Parameter, and they are related interactively (Sarrett 1998) (Figure 2.2).

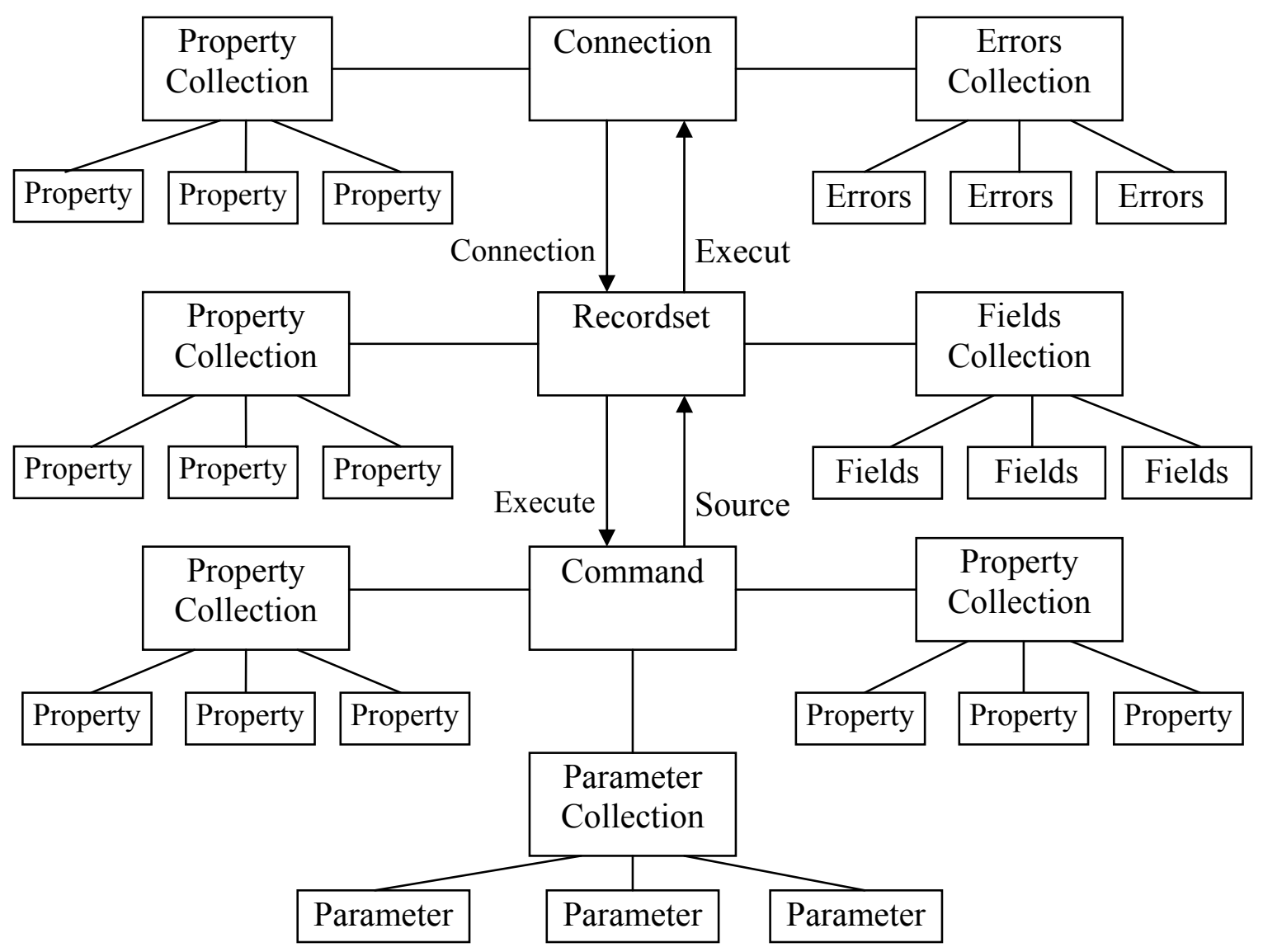

Figure 2.2. Relationship among ADO objects.

The entity-relationship (ER) model is a conceptual data model that views the real world as consisting of entities and relationships (Ullman and Widow 1997). There are three basic concepts in ER model: entity, attribute and relationship. Entities are the principal data objects about which information is to be collected. Each entity is described by several associated attributes. Two or more entities are related by relationship. Entities are represented by tables in the Access database. 
The ER model for the optimal bucking system was implemented via Microsoft Access, including five entities: stems, shapes, grades and prices, defects, and logs. Five relationships among these entities were defined in the ER model, which reflect the interrelationships among these entities. For each entity type, several attributes are associated with it (Figure 2.3).

- Stems: to store stem number, and basic stem information

- Logs: to store bucking results

- Defects: to store defects data associated with each stem

- Grades and prices: to store grading rules and price matrix

- Shapes: to store stem sweeps and diameters data at each 4-foot intersections.

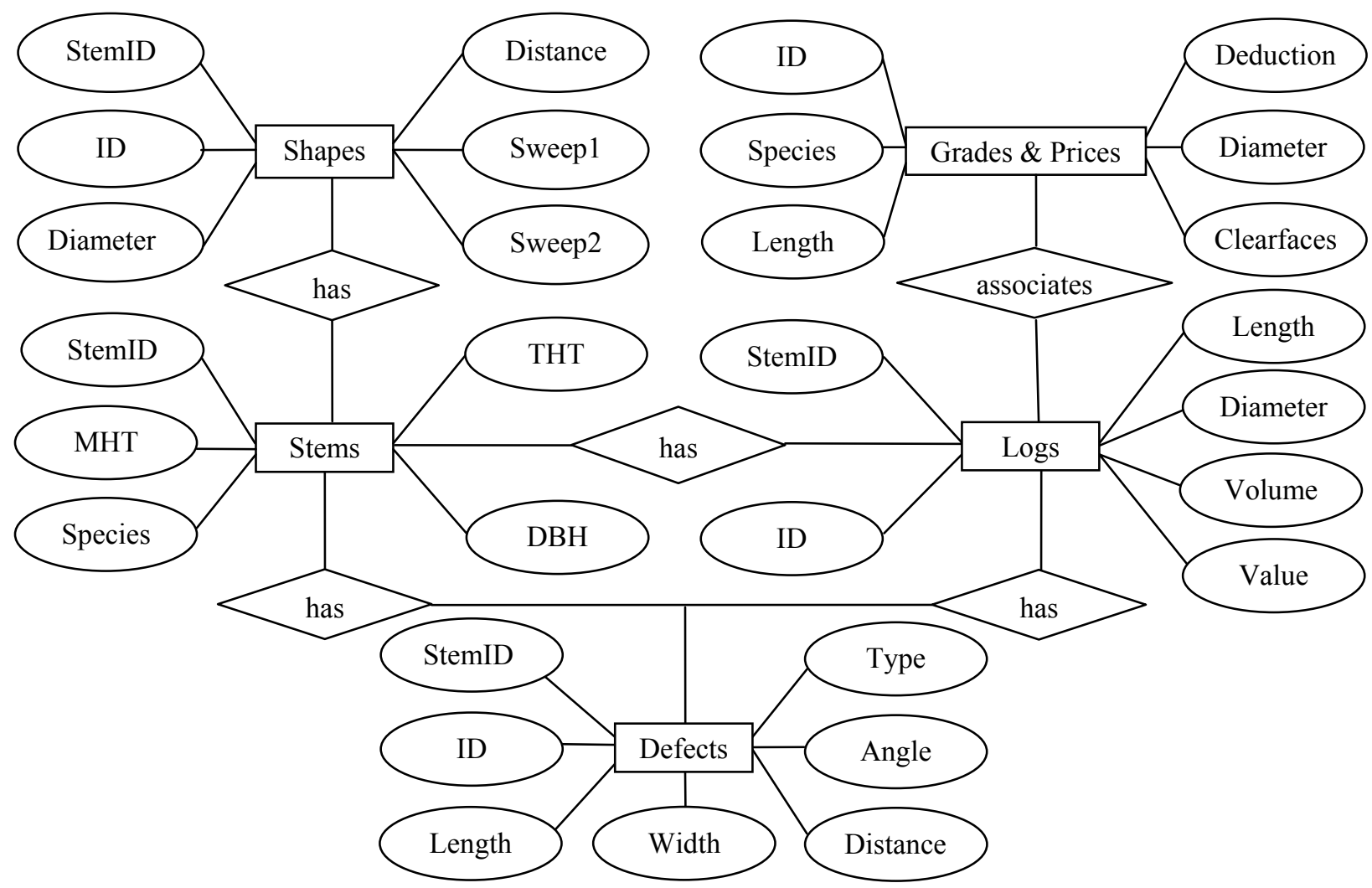

Figure 2.3. ER model of the optimal bucking system. 


\subsubsection{D Tree-Stem Modeling}

In order to provide the user with a realistic tree-stem, 3-D modeling techniques were used together with OpenGL primitives drawing functions. The 3-D tree-stem was composed of simple triangle strips and the strips were filled with stem images, such as bark or the butt end image. The user can perform rotate, translate and scale functions to get a better understanding of the stem's superficial characteristics. The rotate function is invoked by calling glRotate $(\alpha, \mathrm{x}, \mathrm{y}, \mathrm{z})$ which generates the rotation matrix by defining the axis of rotation (x-axis, y-axis or z-axis) and the degrees to be rotated $(\alpha)$. The generic matrix of rotation $\alpha$ angle around the $\mathrm{x}$-axis can be expressed as an equation (2-1) (Woo et al. 2000).

$$
R_{x}(\alpha)=\left[\begin{array}{cccc}
1 & 0 & 0 & 0 \\
0 & \cos \alpha & -\sin \alpha & 0 \\
0 & \sin \alpha & \cos \alpha & 0 \\
0 & 0 & 0 & 1
\end{array}\right]
$$

Let $\mathrm{V}=(\mathrm{x}, \mathrm{y}, \mathrm{z}, 1)^{\mathrm{T}}$ be a vector before rotation, which contains the coordinates of a point and 1 for homogenous coordinate. If $\mathrm{V}$ is rotated by $\alpha$ degree around $\mathrm{x}$-axis, the rotated vector V' can be expressed as equation (2-2).

$$
V^{\prime}=R_{x}(\alpha) \times V
$$$$
\left[\begin{array}{c}
x^{\prime} \\
y^{\prime} \\
z^{\prime} \\
1
\end{array}\right]=\left[\begin{array}{cccc}
1 & 0 & 0 & 0 \\
0 & \cos \alpha & -\sin \alpha & 0 \\
0 & \sin \alpha & \cos \alpha & 0 \\
0 & 0 & 0 & 1
\end{array}\right]_{R_{x}} \times\left[\begin{array}{c}
x \\
y \\
z \\
1
\end{array}\right]=\left[\begin{array}{c}
x \\
y \cos \alpha-z \sin \alpha \\
y \sin \alpha+z \cos \alpha \\
1
\end{array}\right]
$$ 
So $V^{\prime}=\left(x^{\prime}, y^{\prime}, z^{\prime}, 1\right)^{T}=(x, y \cos \alpha-z \sin \alpha, y \sin \alpha+z \cos \alpha, 1)^{T}$. Let the coordinates of the vertices of a triangle (basic unit for a tree-stem) be $\left(\mathrm{x}_{1}, \mathrm{y}_{1}, \mathrm{z}_{1}\right),\left(\mathrm{x}_{2}, \mathrm{y}_{2}, \mathrm{z}_{2}\right),\left(\mathrm{x}_{3}, \mathrm{y}_{3}, \mathrm{z}_{3}\right)$, respectively. The coordinate matrix for this triangle after rotating by $\alpha$ degrees around the $\mathrm{X}$-axis can be expressed as equation (2-3):

$$
\begin{aligned}
& {\left[\begin{array}{ccc}
x_{1}^{\prime} & x_{2}^{\prime} & x_{3}^{\prime} \\
y_{1}^{\prime} & y_{2}^{\prime} & y_{3}^{\prime} \\
z_{1}^{\prime} & z_{2}^{\prime} & z_{3}^{\prime} \\
1 & 1 & 1
\end{array}\right]=R_{x}(\alpha) \times\left[\begin{array}{ccc}
x_{1} & x_{2} & x_{3} \\
y_{1} & y_{2} & y_{3} \\
z_{1} & z_{2} & z_{3} \\
1 & 1 & 1
\end{array}\right]} \\
& T S^{\prime}=R_{x}(\alpha) \times T S
\end{aligned}
$$

Where, TS is the coordinate matrix for one triangle before transformation and $T S^{\prime}$ is the coordinate matrix for this triangle after transformation. Similarly, the coordinate matrices for the triangle strip can be rotated around the $y$ and $x$-axes. The scale and translation are performed by calling the gIScale $\left(\mathrm{S}_{\mathrm{x}}, \mathrm{S}_{\mathrm{y}}, \mathrm{S}_{\mathrm{z}}\right)$ and glTranslate $(\mathrm{dx}, \mathrm{dy}, \mathrm{dz})$ functions. $\mathrm{S}_{\mathrm{x}}, \mathrm{S}_{\mathrm{y}}, \mathrm{S}_{\mathrm{z}}$ are the scales to $\mathrm{x}, \mathrm{y}, \mathrm{z}$ coordinate of the stem while $\mathrm{dx}, \mathrm{dy}$, $\mathrm{dz}$ are the units of distances to be translated along the $\mathrm{x}$-axis, $\mathrm{y}$-axis and $\mathrm{z}$-axis, respectively.

\subsubsection{Optimal Bucking Algorithm}

A network analysis technique (Dykstra 1984, Näsburg 1985, Sessions 1988) was

implemented in the system to generate the optimal bucking patterns. A series of potential cutting points are defined based on a given stage interval and denoted by $\mathrm{X}_{\mathrm{i}}(\mathrm{i}=0,1,2, \ldots$, n). The distance between two adjacent cutting points is the stage interval and the first 
potential cutting point is the origin and the last potential cutting point is the destination along a tree-stem. The "shortest" path form the $\mathrm{i}^{\text {th }}$ cutting point $\left(\mathrm{X}_{i}\right)$ to the origin $\left(\mathrm{X}_{1}\right)(\mathrm{i}$ $=1,2, \ldots, \mathrm{n})$ needs to be achieved and this procedure is repeated until the $\mathrm{n}^{\text {th }}$ cutting point - the destination $\left(\mathrm{X}_{n}\right)$, is reached. Stem value is presented as V. The maximum value for each cutting point is presented by $V_{i}(i=1,2, \ldots n)$. For each solved node $V_{i}$, a series of previous solved nodes are defined as $\mathrm{V}_{j}(j=1,2, \ldots, i-1)$. Each solved node that is directly connected by a link to one or more unsolved nodes $\left(\mathrm{X}_{j}\right)$ provides one candidate-the unsolved node with the "shortest" connection link. The value between one solved node and one unsolved node is defined as the weight $\mathrm{W}(j, i)$ for this arc. The whole process can be expressed in equation (2-4) form:

$$
\left\{\begin{array}{l}
V=\max \left(V_{i}\right) \\
V_{i}=\max \left\{V_{j}+W(j, i)\right\} \\
i=1,2, \ldots, n \\
j=1,2, \ldots, i-1
\end{array}\right.
$$




\section{CHAPTER 3: OPTIMAL BUCKING SYSTEM IMPLEMENTATION}

\subsection{Sites and Stem Data}

Field measurements were carried out to collect stem dimension, shapes, defects, and bucking results. A total of 264 stems were measured in 5 sites located throughout West Virginia. Each site had only one working crew performing the operations during our field measurements. Two manual and three mechanical harvesting operations were investigated during the study. Bucking was performed by one bucker using a bucksaw. The bucker's experience varied from 14 to 20 years (Table 3.1).

Table 3.1. Site descriptions.

\begin{tabular}{|c|c|c|c|c|c|}
\hline \multirow{2}{*}{ Site } & \multicolumn{4}{|c|}{ Machines } & \multirow{2}{*}{$\begin{array}{l}\text { Bucker's } \\
\text { experience }\end{array}$} \\
\hline & Felling & Skidding & Bucking & Loading & \\
\hline 1 & Timbco & $\begin{array}{c}\text { John Deere } 648 \mathrm{G} \\
\text { Timberjack } 460 \mathrm{G} \\
\text { Caterpillar } 517\end{array}$ & $\begin{array}{l}\text { CTR Bucksaw } \\
\text { Barko 395ML }\end{array}$ & Barko 395ML & 14 years \\
\hline 2 & $\begin{array}{l}\text { Husqvarna } \\
372 \text { XP }\end{array}$ & $\begin{array}{c}\text { John Deere } 540 \mathrm{~B} \\
\text { Case } 650 \mathrm{G}\end{array}$ & $\begin{array}{l}\text { CTR Bucksaw } \\
\text { Serco } 200 \mathrm{~F}\end{array}$ & Serco $200 F$ & 20 years \\
\hline 3 & TIMBCO & $\begin{array}{c}\text { John Deere } 648 \mathrm{G} \\
\text { Timberjack } 460 \mathrm{G} \\
\text { Caterpillar } 517\end{array}$ & $\begin{array}{l}\text { CTR Bucksaw } \\
\text { Barko 395ML }\end{array}$ & Barko 395ML & 14 years \\
\hline 4 & $\begin{array}{l}\text { Husqvarna } \\
372 \text { XP }\end{array}$ & $\begin{array}{c}\text { John Deere 540B } \\
\text { Case } 650 \mathrm{G}\end{array}$ & $\begin{array}{l}\text { CTR Bucksaw } \\
\text { Serco } 200 \mathrm{~F}\end{array}$ & Serco $200 F$ & 15 years \\
\hline 5 & $\begin{array}{l}\text { Timbco } \\
\text { 445XL }\end{array}$ & $\begin{array}{c}\text { CAT 525B } \\
\text { TimberJack } 460\end{array}$ & $\begin{array}{c}\text { CTR Bucksaw } \\
\text { Prentice } 384\end{array}$ & Prentice 384 & 20 years \\
\hline
\end{tabular}

All stems were measured with diameter calipers and 100-foot tape. Diameters were measured at 4-foot interval. Total length and merchantable length were also measured. Each defect was recorded for type, location, and size. Defect types include bark distortion (BD), bulge (BU), split (ST), stain (ST), and hole (HO). BD, BU, and ST are grading defects, which can cause lower log grades. ST and HO are scaling defects, which can cause volume deductions. To measure sweep, two stickers were nailed on both ends of surfaces in the same direction and a string was tightening to these two 
stickers at the same height to the surfaces of the stem. This height was called the base height. At each 4-foot interval, we measured the distances between the string and the surface of the stem and subtracted it from the base height. We turned the string 90 degrees from its previous direction, then measured and subtracted the distances from the base height again. All data were recorded on spread sheets and were then saved to database.

Six hardwood species were observed during our field studies. They are black oak (Quercus kelloggii), chestnut oak (Quercus prinus), red oak (Quercus rubra), white oak (Quercus alba), scarlet oak (Quercus coccinea), and yellow-poplar (Liriodendron tulipifera). They were grouped into YP (yellow-poplar), oaks (red, black, chestnut, white and scarlet oaks) based on their physical characteristics, number of observations, and prices.

Outside bark diameters were converted into inside bark diameters based on a constant ratio for each species for volume calculation. The ratios used to make these conversions were 0.90 for yellow-poplar, 0.929 for red oak, 0.937 for white oak, 0.925 for black oak, 0.909 for chestnut oak, and 0.939 for scarlet oak (Harrison et al. 1986). The number of trees measured at each site ranged from 29 to 60. Yellow-poplar accounted for $54.92 \%$ and the oak species accounted for $45.08 \%$ (Table 3.2). Among these 264 tree-stems, DBH varied from 11.8 to 35.3 inches with an average of 17.8 inches. Merchantable height ranged from 31.6 and 98.0 feet with an average of 56.2 feet (Table 3.3). The sizes of stems varied among species (Tables 3.4, 3.5). Defects statistics for each species class were very similar (Table 3.6). 
Table 3.2. Species distribution by site.

\begin{tabular}{cccc}
\hline Site & Yellow-poplar & Oaks & $\begin{array}{c}\text { Total number } \\
\text { of trees }\end{array}$ \\
\hline 1 & 28 & 30 & 58 \\
2 & 29 & 0 & 29 \\
3 & 29 & 29 & 58 \\
4 & 30 & 30 & 60 \\
5 & 29 & 30 & 59 \\
\% of total number of trees & 54.92 & 45.08 & 100 \\
\hline
\end{tabular}

Table 3.3. DBH and MHT statistics by site.

\begin{tabular}{|c|c|c|c|c|c|c|c|c|c|}
\hline \multirow[b]{2}{*}{ Site } & \multirow{2}{*}{$\begin{array}{l}\text { No. of } \\
\text { stems }\end{array}$} & \multicolumn{4}{|c|}{ DBH (inches) } & \multicolumn{4}{|c|}{ MHT (feet) } \\
\hline & & Mean & $\begin{array}{c}\text { Std } \\
\text { Dev. }\end{array}$ & Min. & Max. & Mean & $\begin{array}{c}\text { Std } \\
\text { Dev. }\end{array}$ & Min. & Max. \\
\hline 1 & 58 & 14.9 & 2.0 & 11.8 & 20.1 & 45.0 & 10.0 & 32.0 & 64.0 \\
\hline 2 & 29 & 18.2 & 2.6 & 11.9 & 23.0 & 71.3 & 15.0 & 40.0 & 98.0 \\
\hline 3 & 58 & 19.3 & 3.8 & 13.9 & 27.3 & 61.6 & 13.9 & 33.4 & 94.9 \\
\hline 4 & 60 & 18.5 & 4.1 & 12.7 & 35.3 & 58.4 & 13.7 & 31.6 & 90.9 \\
\hline 5 & 59 & 18.4 & 2.4 & 14.0 & 24.7 & 52.4 & 9.4 & 33.2 & 74.0 \\
\hline
\end{tabular}

Table 3.4. DBH and MHT statistics by species.

\begin{tabular}{|c|c|c|c|c|c|c|c|c|c|}
\hline \multirow[b]{2}{*}{ Species } & \multirow{2}{*}{$\begin{array}{l}\text { No. of } \\
\text { stems }\end{array}$} & \multicolumn{4}{|c|}{ DBH (inches) } & \multicolumn{4}{|c|}{ MHT (feet) } \\
\hline & & Mean & $\begin{array}{l}\text { Std } \\
\text { Dev. }\end{array}$ & Min. & Max. & Mean & $\begin{array}{c}\text { Std } \\
\text { Dev. }\end{array}$ & Min. & Max. \\
\hline $\begin{array}{l}\text { Yellow- } \\
\text { poplar }\end{array}$ & 145 & 18.1 & 3.7 & 11.9 & 35.3 & 63.8 & 13.6 & 34.6 & 98.0 \\
\hline Oak & 119 & 17.4 & 3.3 & 11.8 & 26.7 & 47.0 & 9.7 & 31.6 & 67.9 \\
\hline
\end{tabular}

Table 3.5. DBH and MHT class distribution by species.

\begin{tabular}{lccc}
\hline Classes & Yellow-poplar & Oak & \% of total number of trees \\
\hline \multicolumn{3}{c}{ DBH class } \\
$<15$ inches & 29 & 29 & 22.0 \\
$15-20$ inches & 64 & 82 & 55.3 \\
$20-25$ inches & 23 & 28 & 19.3 \\
$>=25$ inches & 3 & 6 & 3.4 \\
& & MHT class & \\
& 2 & 21 & 8.7 \\
$<40$ feet & 23 & 54 & 29.2 \\
$40-50$ feet & 35 & 30 & 18.9 \\
$50-60$ feet & 36 & 14 & 18.6 \\
$60-70$ feet & 49 & 0 & \\
$>=70$ feet & & & \\
\hline
\end{tabular}


Table 3.6. Average number and size of defects statistics by species.

\begin{tabular}{lccccccccc}
\hline \multirow{2}{*}{ Species } & $\begin{array}{c}\text { No. of } \\
\text { stems }\end{array}$ & \multicolumn{4}{c}{ Number of defects } & \multicolumn{4}{c}{ Size of defects(inches) } \\
\cline { 3 - 11 } & Mean & $\begin{array}{c}\text { Std } \\
\text { Dev. }\end{array}$ & Min. & Max. & Mean & $\begin{array}{c}\text { Std } \\
\text { Dev. }\end{array}$ & Min. & Max. \\
\hline $\begin{array}{l}\text { Yellow- } \\
\text { poplar }\end{array}$ & 145 & 8.28 & 4.52 & 1 & 27 & 5.46 & 1.99 & 2 & 13 \\
Oak & 119 & 8.33 & 3.95 & 1 & 23 & 5.94 & 3.19 & 2 & 32 \\
\hline
\end{tabular}

\subsection{Scaling Rules}

Two major log scaling rules were used in the system: Doyle and International 1/8 $\log$ rule. The Doyle log rule is the most common log rule used in hardwood scaling. It was developed prior to 1825 by E. Doyle. It assumes a saw kerf of 5/16 inch and a 4inch slab deduction. This rule estimates the volume of log based on log length, scaling diameter, slabs, edgings, shrinkage and production of sawdust (Avery and Burkhart 2001).

$$
V(\text { bd.ft. })=\frac{(D-4)^{2} L}{16}
$$

Where, $\mathrm{D}$ is the diameter inside bark measured in inches at small end of the log and $\mathrm{L}$ is nominal log length measured in feet. There is no allowance for taper.

Devised by Judson Clark in 1906 (Avery and Burkhart 2001), the International $\log$ rule was based on a reasonably accurate mathematical formula. It includes a fixed log taper allowance of $1 / 2$ inch per 4 feet of log length. To scale the volume of a 16 feet log, simply sum the volume of each 4 feet long cylinder, each $1 / 2$ inch larger in diameter than the previous one. For International 1/8 inch rule, saw kerf is assumed 1/8 inch, plus 1/16 inch allowance for board shrinkage, the total deduction is $3 / 16$ inch.

Assuming the saw kerf is $1 / 8$ inch, the log volume equations for the International $\log$ rule are:

For 4-foot lengths: $\mathrm{V}($ bd.ft. $)=\left(0.22 \mathrm{D}^{2}-0.71 D\right)$ 
For 8-foot lengths: V(bd.ft. $)=\left(0.44 D^{2}-1.2 D-0.3\right)$

For 12-foot lengths: $\mathrm{V}($ bd.ft. $)=\left(0.66 \mathrm{D}^{2}-1.47 D-0.79\right)$

For 16-foot lengths: V(bd.ft. $)=\left(0.88 \mathrm{D}^{2}-1.52 D-1.36\right)$

Where, $\mathrm{D}$ is the diameter inside bark measured in inches at small end of the log.

\subsection{Grading Rules and Price Matrix}

Mail surveys of grading rules and price matrixes were sent to saw mills in the central Appalachian region. The survey results were summarized. Logs are usually classified as veneer, prime, select common, and under common class according to size, species, position in tree-stem, and defects. Although there are differences between saw mills, the minimum 8 feet length and 10 inch small end diameter are the same requirements for saw and veneer logs. The grading rules and corresponding price matrix were set as the default rules and prices in the optimal bucking system (Tables 3.7, 3.8).

Table 3.7. Log grading rules.

\begin{tabular}{llllll}
\hline Grade & $\begin{array}{l}\text { Minimum } \\
\text { diameter(in.) }\end{array}$ & $\begin{array}{l}\text { Minimum } \\
\text { length(ft.) }\end{array}$ & Species & Position & Clearfaces \\
\hline Veneer & 16 & 8 & WO, RO, YP & Butt & 4 \\
Prime & 12 & 8 & Any & Any & 4 \\
Select & 12 & 8 & Any & Any & 3 \\
Common & 12 & 8 & Any & Any & 2 \\
Below & 10 & 8 & Any & Any & 1 \\
Common & & & & & \\
\hline
\end{tabular}

For all grades, a 3-inch trim allowance is required. Log length will be rounded down to the nearest even feet length for all species except yellow-poplar. For example, $\log$ having a length of 15.2 feet will be measured as a 14 -foot $\log$ with trim. The maximum log length is 16 feet. For yellow-poplar, the log length will be rounded to the nearest foot. For example, a yellow-poplar log with length of 9.8 feet will be graded as 9foot long log with trim. 
A scale deduction of 1-inch in diameter will be made for every 3 -inch sweep. A scale deduction of 1-inch diameter will be made for every 3-inch diameter hole or rot in the end of the log. Logs that have more than 50\% scale deduction are considered cull. Diameters of logs are rounded to the nearest integer diameter for volume calculation, i.e. $\log$ with diameter of 13.2 inches will be rounded to 13 inches and $\log$ diameter of 13.6 inches also will be rounded to 13 inches. Log lengths were also rounded to the nearest acceptable grade length plus 3 inches trim allowance, i.e. log with length of 12 feet and 9 inches will be rounded to 12 feet with 3 inches trim. A yellow poplar log with length of 10 feet and 2 inches will be rounded to 9 feet with 3 inches trim. The same length log of red oak species will be rounded to 8 feet with 3 inches trim.

Table 3.8. Log grades and prices (\$/MBF).

\begin{tabular}{|c|c|c|c|c|c|c|c|c|c|}
\hline \multirow{3}{*}{$\begin{array}{l} \\
\text { Diameter } \\
\text { Length }\end{array}$} & \multirow{3}{*}{$\begin{array}{c}\begin{array}{c}\text { Veneer } \\
\text { (No defect) }\end{array} \\
16^{\prime} \text { \& up } \\
8^{\prime}-16^{\prime}\end{array}$} & \multicolumn{4}{|c|}{$\begin{array}{c}\text { Prime } \\
\text { (4 clearfaces })\end{array}$} & \multicolumn{4}{|c|}{$\begin{array}{c}\text { Select } \\
(3 \text { clearfaces }) \\
\end{array}$} \\
\hline & & \multicolumn{2}{|c|}{$16 "$ \& up } & \multicolumn{2}{|c|}{$12 " \& u p$} & \multicolumn{2}{|c|}{$16 " \&$ up } & \multicolumn{2}{|c|}{$12 "$ \&up } \\
\hline & & $14^{\prime}-16^{\prime}$ & $10-12$ & $10^{\circ}-16^{\prime}$ & 8 & $14^{\prime}-16^{\prime}$ & $10^{\prime}-12^{\prime}$ & $10^{\prime}$ to $16^{\prime}$ & 8 \\
\hline $\mathrm{CO}$ & - & 500 & 450 & 350 & 300 & 450 & 400 & 300 & 275 \\
\hline WO & 1100 & 600 & 475 & 375 & 325 & 450 & 400 & 300 & 275 \\
\hline RO & 1200 & 900 & 800 & 550 & 450 & 800 & 625 & 450 & 350 \\
\hline $\mathrm{SO}$ & - & 400 & 325 & 300 & 275 & 350 & 300 & 275 & 250 \\
\hline $\mathrm{BO}$ & - & 700 & 600 & 400 & 325 & 600 & 400 & 300 & 275 \\
\hline YP & 550 & 400 & 400 & 350 & 350 & 250 & 250 & 250 & 250 \\
\hline \multicolumn{10}{|l|}{ (cont'd) } \\
\hline & \multicolumn{4}{|c|}{$\begin{array}{c}\text { Common } \\
(2 \text { clearfaces }) \\
\end{array}$} & \multicolumn{5}{|c|}{$\begin{array}{l}\text { Below Common } \\
\text { (1 clearface) }\end{array}$} \\
\hline Diameter & \multicolumn{2}{|c|}{$16 " \&$ up } & \multicolumn{2}{|c|}{$12 "$ \& up } & \multicolumn{2}{|c|}{$16 " \&$ up } & \multicolumn{3}{|c|}{$10 "$ \& up } \\
\hline Length & $14^{\prime}-16^{\prime}$ & $10^{\prime}-12^{\prime}$ & $10^{\prime}-16^{\prime}$ & 8 & $14^{\prime}-16^{\prime}$ & $10^{\prime}-12^{\prime}$ & $10^{\prime}-16^{\prime}$ & 8 & \\
\hline $\mathrm{CO}$ & 400 & 350 & 275 & 250 & 350 & 300 & 250 & 225 & \\
\hline WO & 400 & 350 & 275 & 250 & 350 & 300 & 250 & 225 & \\
\hline RO & 550 & 450 & 350 & 250 & 425 & 350 & 250 & 225 & \\
\hline SO & 300 & 275 & 250 & 225 & 275 & 250 & 250 & 225 & \\
\hline $\mathrm{BO}$ & 400 & 300 & 275 & 250 & 300 & 275 & 250 & 225 & \\
\hline YP & 200 & 200 & 200 & 200 & 125 & 125 & 125 & 125 & \\
\hline
\end{tabular}




\subsection{Application Example}

After running the optimal bucking program, users need to click the optimal bucking command under the "run" menu in the menu bar. The stem list dialog will pop up for user's selection. There are four tab controls labeled as "Stems", "Defects", "Shapes" and "Grades". The "Stem" tab is used to display all stem data saved in the database. To view the defects, shapes and grade information associated with a selected stem, in this case stem 1, the user can click the corresponding tab controls (Figure 3.1).
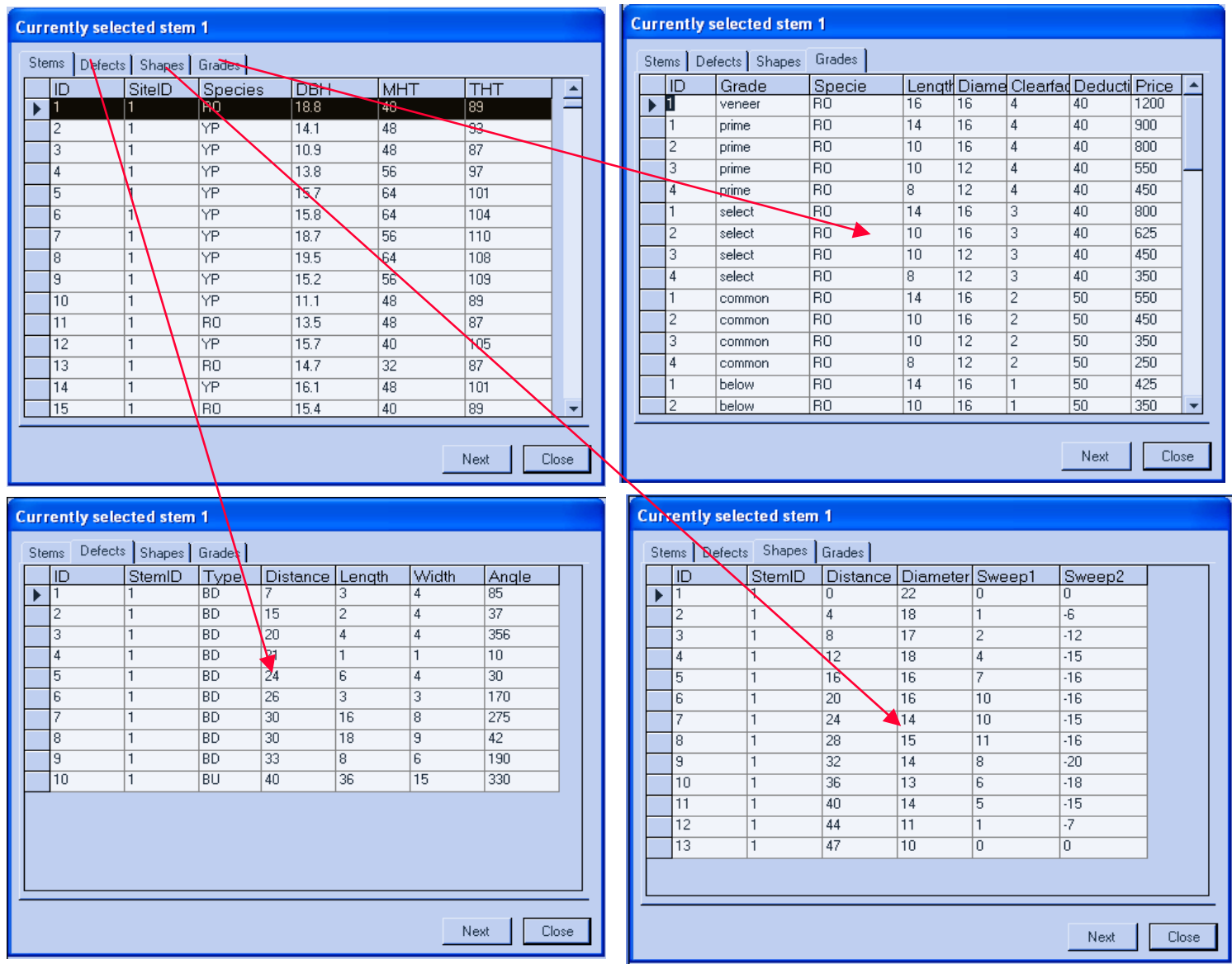

Figure 3.1. Relationships between tree-stem, defects, shapes and grades.

After selecting a stem, the user can click the "Next" button at lower right corner of the box. A 3-D tree-stem image will be generated (Figure 3.2). The 3-D display dialog 
is divided into three major sections: display area (top area), information area (bottom left area) and command area (bottom right area).

The display area is for displaying the 3-D stem image and viewing the bucking results of the selected stem. The 3-D stem image is displayed in the middle of display area. Text in the upper left corner of the display area was used for the updated inside bark diameter and length from the previous cut to the current cut position. In this case, the saw is at the butt end of the stem and the associated inside bark diameter of this stem is 20 inches. There are also six command buttons in the display area including "Left move", "Right move", "Zoom in", “Zoom out", "Rotate along x-axis", and "Rotate along z-axis". By clicking these buttons, the user can view the displayed stem from different view perspective and angles. This will allow the user to have a better understanding of the stem defects and shape when performing manual bucking. Defects of the stem are shown as red rectangles in the display area. The sizes and locations of the red rectangles represent the actual defects locations and sizes which are either measured in the field or entered by the user.

Below the display area is the information area which shows the basic information for a selected stem and the detailed bucking results. Options were provide to users for $\log$ rules and bucking methods in command area. When the user selects optimal bucking, a stage interval should be chosen from the drop down list. If manual bucking is selected, this drop list for stage interval selection will be disabled. All the log volume will be calculated based on the selected scaling rule: Doyle or International $1 / 8 "$. On the bottom left of command area there are two check boxes for displaying or hiding coordinate and defect data. Three command buttons "Buck", "Save" and "Cancel" on the bottom right 
corner of command area are used for bucking, saving bucking results and closing the display dialog.

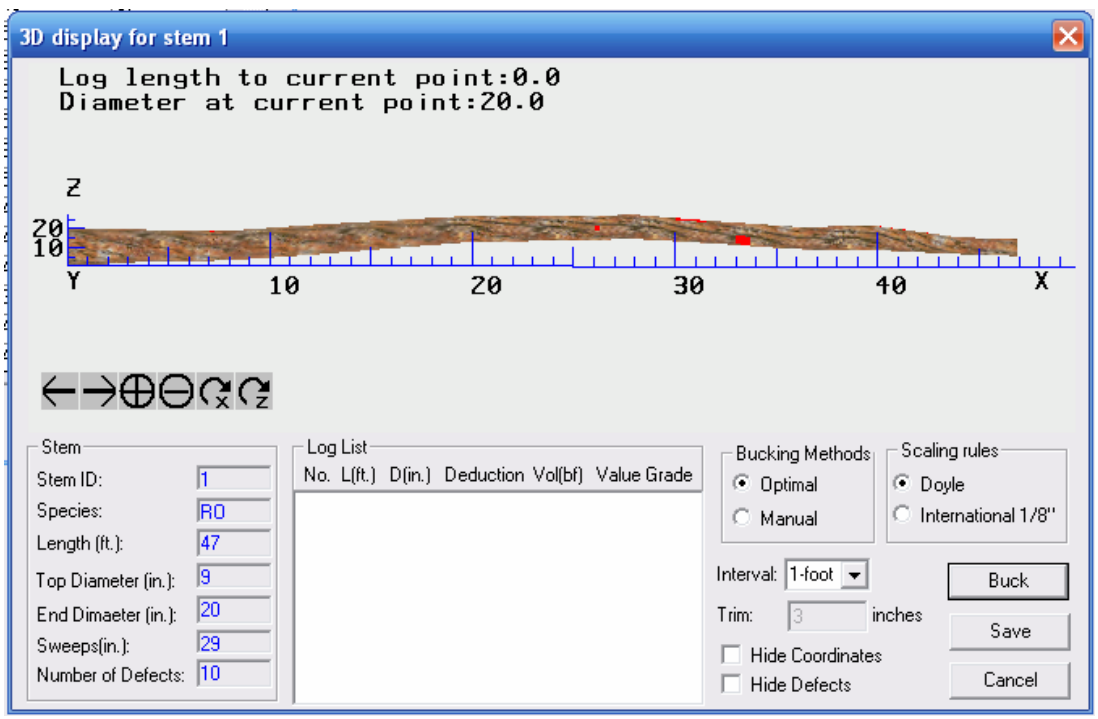

Figure 3.2. 3-D stem display dialog.

Figure 3.3 shows the result of manual bucking. According to the field records, stem 1 was red oak and was bucked into 4 logs having lengths of 16-foot, 10-foot, 10-foot and 10-foot. The total log value for stem 1 is $\$ 71$ and the total volume of logs bucked from stem 1 is 187 $\mathrm{BF}$. The log length for the fourth $\log$ in the $\log$ list is 0 instead of 10 feet because this $\log$ is not a grade log. Therefore, the grading length of this log is assigned to 0 .

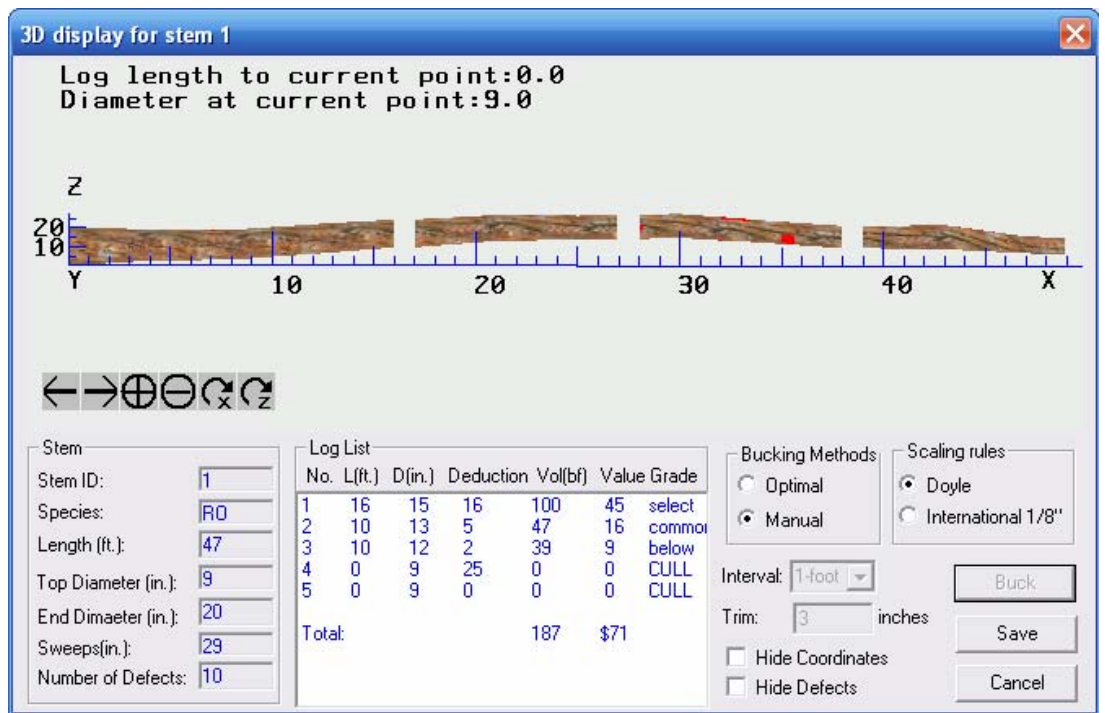

Figure 3.3. Manual bucking example. 
Figure 3.4 shows the bucking result of optimal bucking. The stage interval selected is 1-foot. The total log value for stem 1 is $\$ 105$ and total log volume is $222 \mathrm{BF}$. The optimal bucking yields four logs having lengths of 12-foot, 10-foot, 8-foot and 10foot. The user can save the results by clicking the "Save" button. Otherwise, by clicking "Cancel", the user can perform another bucking operation using different methods or stage intervals.

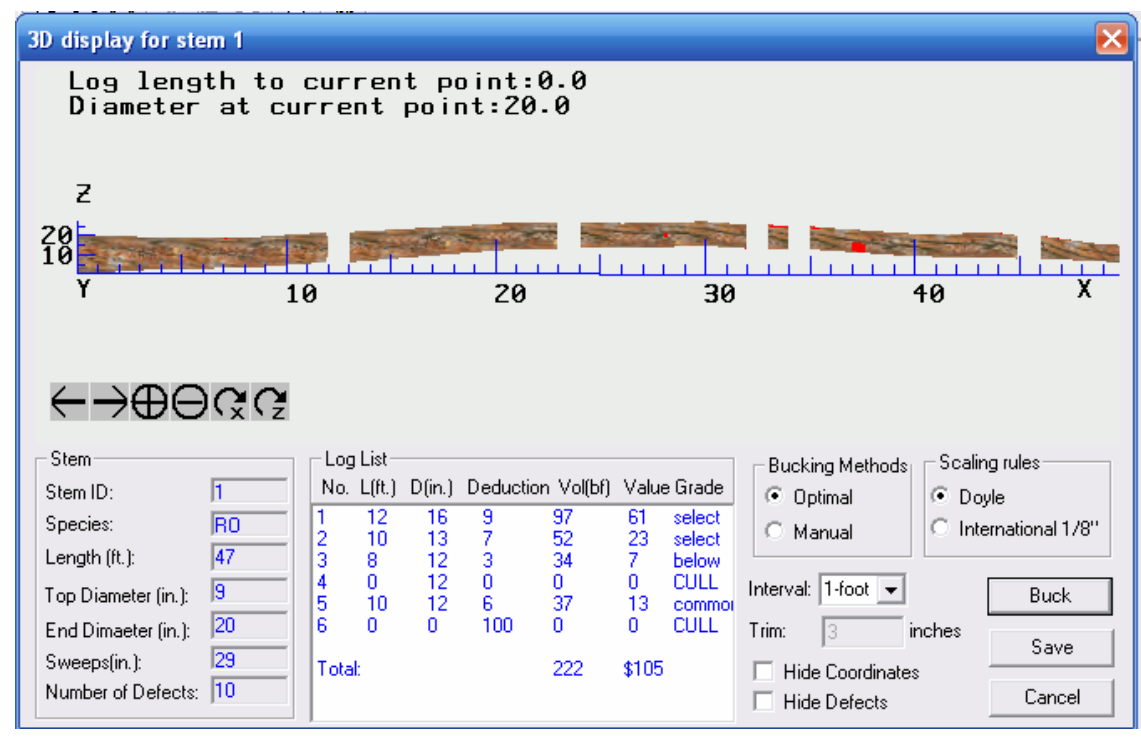

Figure 3.4. Optimal bucking example. 


\section{CHAPTER 4: ANALYSIS AND RESULTS}

\subsection{System Execution Time}

All bucking experiments with this 3-D system were performed on a regular desktop PC equipped with Pentium IV 3.60 GHz CPU, 1.0 GB RAM, 80 GB hard drive using the Microsoft Windows XP Professional Operating System. The average running time for 4-foot, 1-foot, 4-inch and 1-inch stage intervals were 15, 189, 1620 and 25525.23 milliseconds, respectively. The execution time approximated a near to negative exponential relationship to stage interval (Figure 4.1). When stage interval decreased from 4-foot to 1-foot, 4-inch, and 1-inch, system execution time increased 13, 108, and 1702 times, respectively.

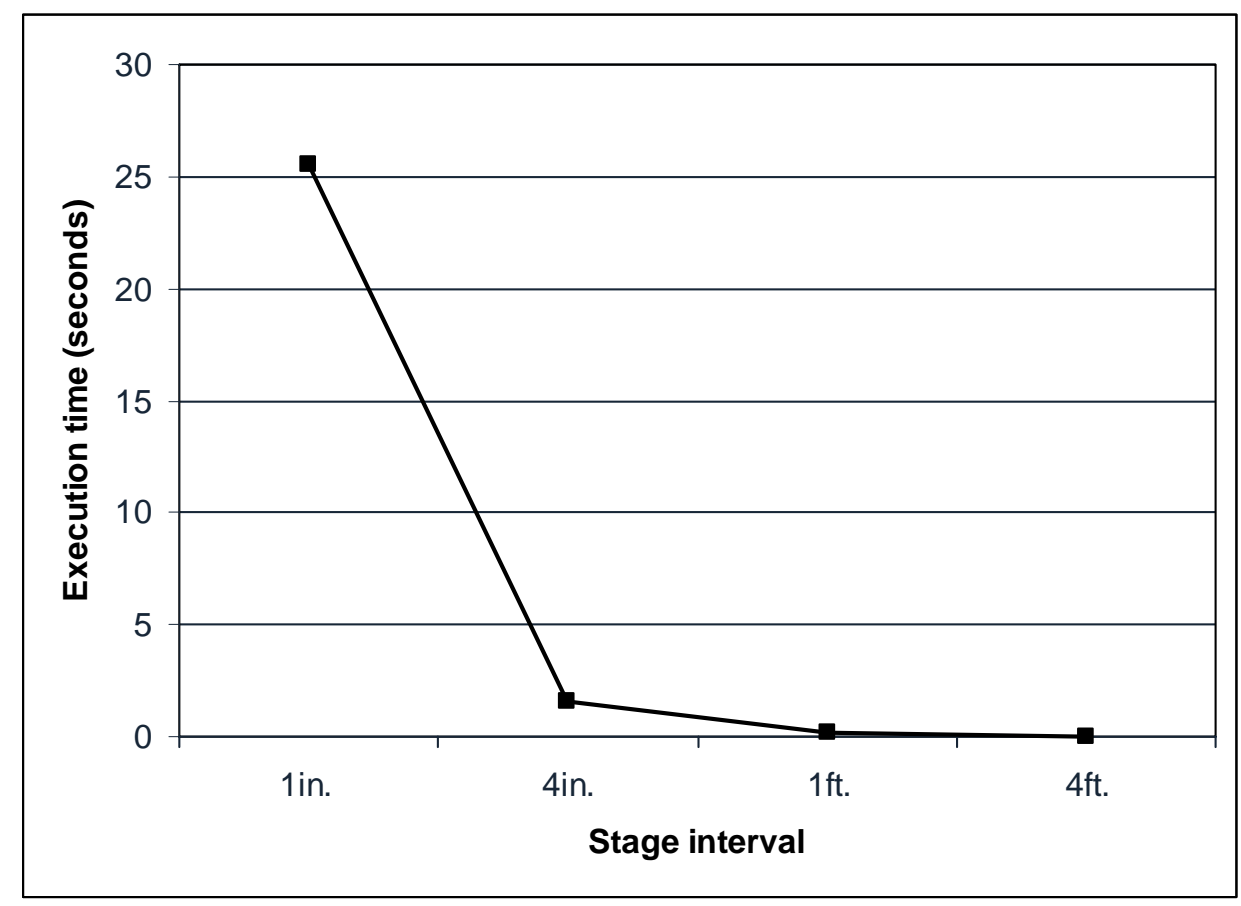

Figure 4.1. System execution time vs. stage interval of optimal bucking.

Factors like species, DBH, MHT, stage interval, number of defects and size of defect can also influence system execution time. At the $\alpha=0.05$ level, stage intervals 
$(\mathrm{p}<0.0001)$ and number of defects $(\mathrm{p}=0.0081)$ had significant effect on the system execution time.

\subsection{Stem Value and Volume}

\subsubsection{Comparisons of Means}

Logs bucked using different bucking methods were classified into different length and diameter classes based on log grading length and small end diameter. Log distributions by grading diameters for all bucking methods were similar, which were 10 in. and 12 in. grading diameter logs account for about $30 \%$, respectively, and logs with grading diameter of $14 \mathrm{in}$. and $16 \mathrm{in}$. classes accounted for about $20 \%$ of the total log percentages, respectively (Table 4.1). Log distributions for manual bucking and optimal bucking were very different. For optimal bucking methods with different stage interval, $\log$ distributions were very similar. Eight-foot logs obtained using manual bucking accounted for $26.94 \%$ of the total, while for optimal bucking, logs with the same length were between 50.66 and $62.60 \%$. Sixteen-foot logs obtained using manual bucking accounted for $32 \%$ of the total, while logs of the same length were between 5.18 and $6.56 \%$ for optimal bucking (Table 4.2). Compared to manual bucking, optimal bucking produced a higher percentage of 8 feet short logs and a smaller percentage of 16- foot logs.

Table 4.1. Log distribution by grading diameter for different bucking methods.

\begin{tabular}{lcccc}
\hline & 10 in. (\%) & 12 in. (\%) & 14 in. (\%) & 16 in. and up (\%) \\
\hline Manual & 31.52 & 30.52 & 19.87 & 18.09 \\
1 in. & 30.59 & 31.86 & 18.42 & 19.13 \\
4 in. & 30.23 & 31.81 & 18.55 & 19.42 \\
$1 \mathrm{ft}$. & 30.00 & 31.73 & 18.66 & 19.61 \\
$4 \mathrm{ft}$. & 29.30 & 31.56 & 18.52 & 20.63 \\
\hline
\end{tabular}


Table 4.2. Log distribution by grading length for different bucking methods.

\begin{tabular}{lccccc}
\hline & $8 \mathrm{ft} .(\%)$ & $10 \mathrm{ft} .(\%)$ & $12 \mathrm{ft} .(\%)$ & $14 \mathrm{ft} .(\%)$ & $16 \mathrm{ft} .(\%)$ \\
\hline Manual & 26.64 & 20.09 & 13.65 & 7.21 & 32.41 \\
1in. & 50.99 & 21.50 & 17.63 & 4.90 & 4.98 \\
4in. & 51.22 & 21.86 & 16.97 & 4.89 & 5.05 \\
1ft. & 50.87 & 21.73 & 17.56 & 4.80 & 5.04 \\
4ft. & 62.60 & 0 & 30.83 & 0 & 6.56 \\
\hline
\end{tabular}

The average stem value and volume for manual bucking was $\$ 69.43$ and 201.45 BF (Table 4.3). For optimal bucking with 4-foot, 1-foot, 4-inch, and 1-inch stage interval, the average stem value was $\$ 91.23, \$ 94.65, \$ 95.31$, and $\$ 95.61$, respectively, which resulted an increase of $31.39 \%$ to $37.69 \%$ for average stem value when compared to manual bucking. The average stem volume for optimal bucking with 4-foot, 1-foot, 4inch, and 1-inch stage intervals was 233.95 BF, 234.89 BF, 234.17 BF, and 233.75 BF, respectively, which was $16.03 \%$ to $16.60 \%$ higher than that for manual bucking. The stem value/BF by computer bucking with different stage intervals also increased $13.13 \%$ to $18.67 \%$ in comparison with manual bucking (Figure 4.2 ), which simply indicated that optimal bucking could produce higher grade logs than manual bucking. The tree-stem utilization rate was defined as the total length of logs bucked from a stem divided by the stem's MHT. For manual bucking, the average utilization rate was $68.94 \%$, which was about $8 \%$ lower than that of optimal bucking (Table 4.3). The higher tree-stem utilization rates with optimal bucking consequently resulted in the increase of average value and volume of logs bucked per stem compared to manual bucking. 
Table 4.3. Value and volume gains of optimal bucking.

\begin{tabular}{|c|c|c|c|c|c|c|c|c|c|}
\hline & \multirow{3}{*}{$\begin{array}{l}\text { Manual } \\
\text { Bucking }\end{array}$} & \multicolumn{8}{|c|}{ Stage interval for optimal bucking } \\
\hline & & \multicolumn{2}{|c|}{$1 \mathrm{in.}$} & \multicolumn{2}{|c|}{4 in. } & \multicolumn{2}{|c|}{$1 \mathrm{ft}$} & \multicolumn{2}{|c|}{$4 \mathrm{ft}}$. \\
\hline & & Value & $\begin{array}{c}\% \\
\text { change }\end{array}$ & Value & $\begin{array}{c}\% \\
\text { change }\end{array}$ & Value & $\begin{array}{c}\% \\
\text { change }\end{array}$ & Value & $\begin{array}{c}\% \\
\text { change }\end{array}$ \\
\hline $\begin{array}{c}\text { Value/ } \\
\text { stem (\$) }\end{array}$ & 69.43 & 95.61 & 37.69 & 95.31 & 37.28 & 94.65 & 36.32 & 91.23 & 31.39 \\
\hline $\begin{array}{l}\text { Volume/ } \\
\text { stem (BF) }\end{array}$ & 201.45 & 233.75 & 16.03 & 234.17 & 16.24 & 234.89 & 16.60 & $\begin{array}{c}233.9 \\
5\end{array}$ & 16.13 \\
\hline $\begin{array}{l}\text { Value/unit } \\
\text { volume } \\
\text { (\$/BF) }\end{array}$ & 0.34 & 0.41 & 18.67 & 0.41 & 18.09 & 0.40 & 16.92 & 0.39 & 13.13 \\
\hline $\begin{array}{l}\text { Utilization } \\
\text { rate }(\%)\end{array}$ & 71.39 & 79.19 & 10.93 & 79.23 & 10.98 & 79.41 & 11.23 & 78.61 & 10.11 \\
\hline
\end{tabular}

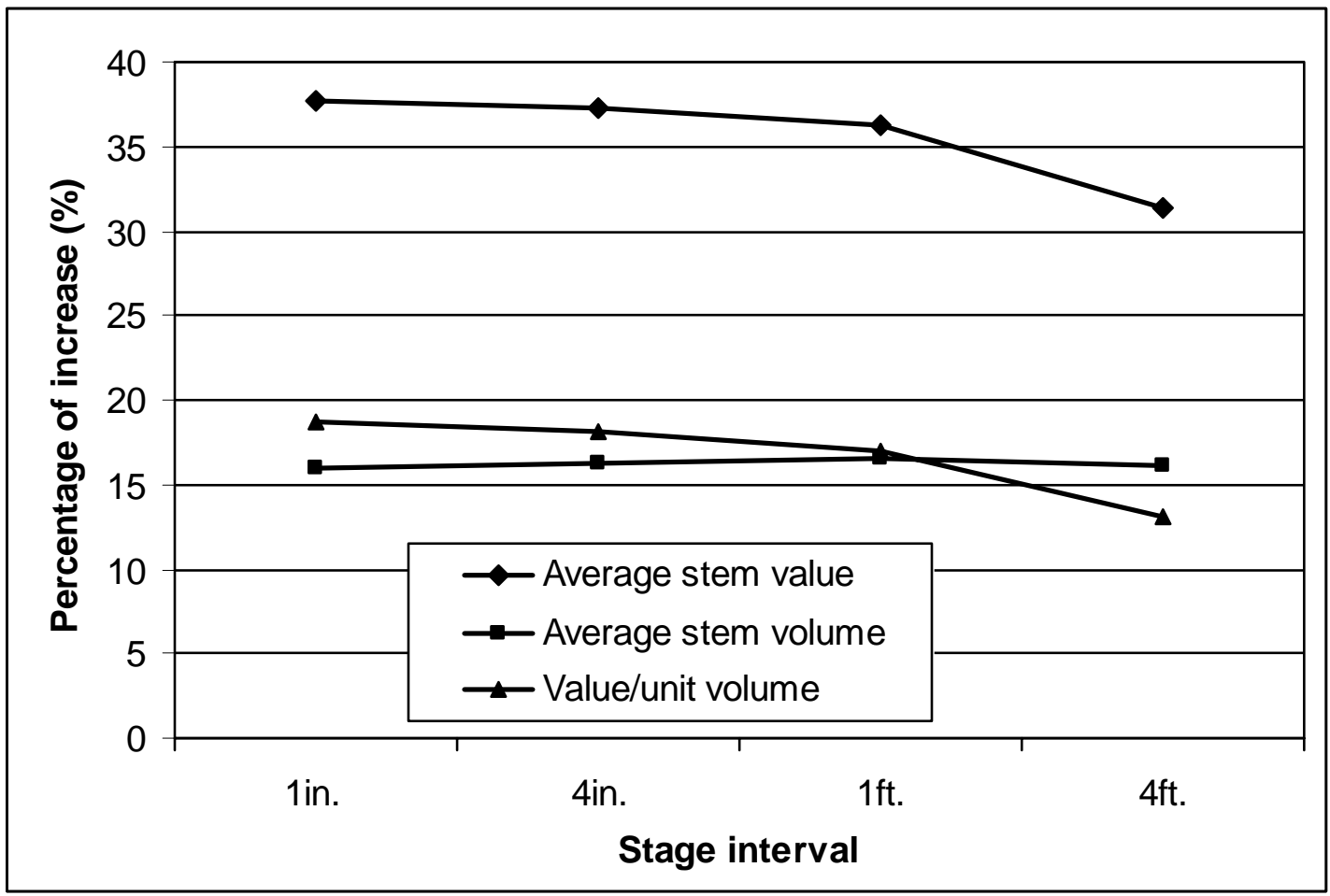

Figure 4.2. Average stem value, volume and value/BF increase by optimal bucking.

When optimally bucking a tree-stem, the general trend was that the bigger DBH a stem has, the more value and higher percentage of value could increase compared to manual bucking (Figure 4.3). For stems with DBH less than 15 inches, because the base value was small, which caused high percentage of value per stem increases. 


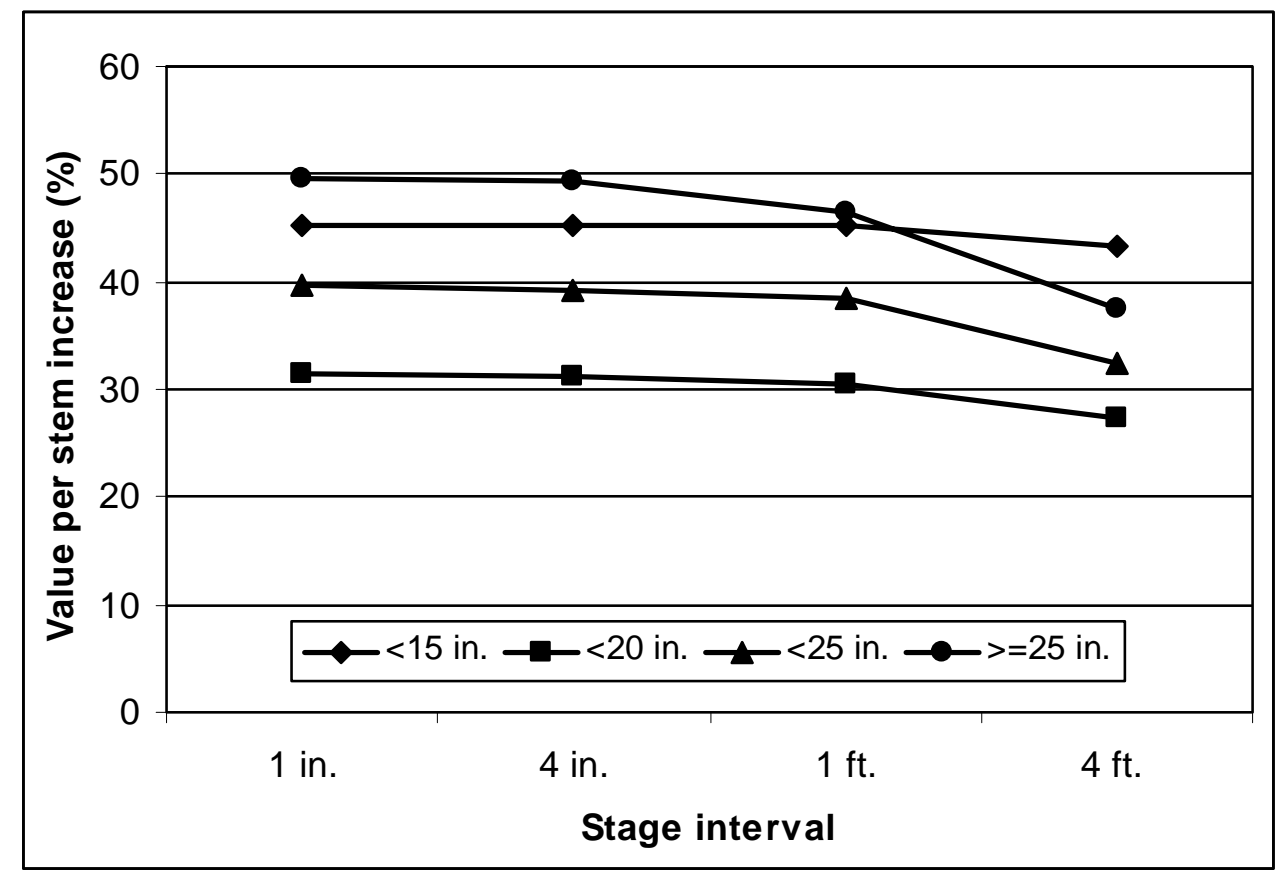

Figure 4.3. Increase of value per stem vs. stage interval by DBH class.

Similarly, the greater the MHT, the higher value per stem and percentage of value per stem increase could obtain during optimal bucking. For example, when optimally bucking tree stems with MHT more than 70 feet, the average stem value increase could be more than $40 \%$, compared to manual bucking. For tree stems with MHT between 30 to 50 feet, only about a $30 \%$ increase for average stem value could be obtained during optimal bucking (Figure 4.3).

Compared to manual bucking, optimal bucking could increase the stem value of oak species slightly higher than yellow-poplar (Figure 4.5). Both oaks and yellow-poplar were the major merchantable species in this region. Oaks are the more valuable species and generally have more defects and irregular shape than yellow-poplar. Buckers usually pay more attention when bucking oaks than when bucking less valuable and more uniformed yellow-poplar. 


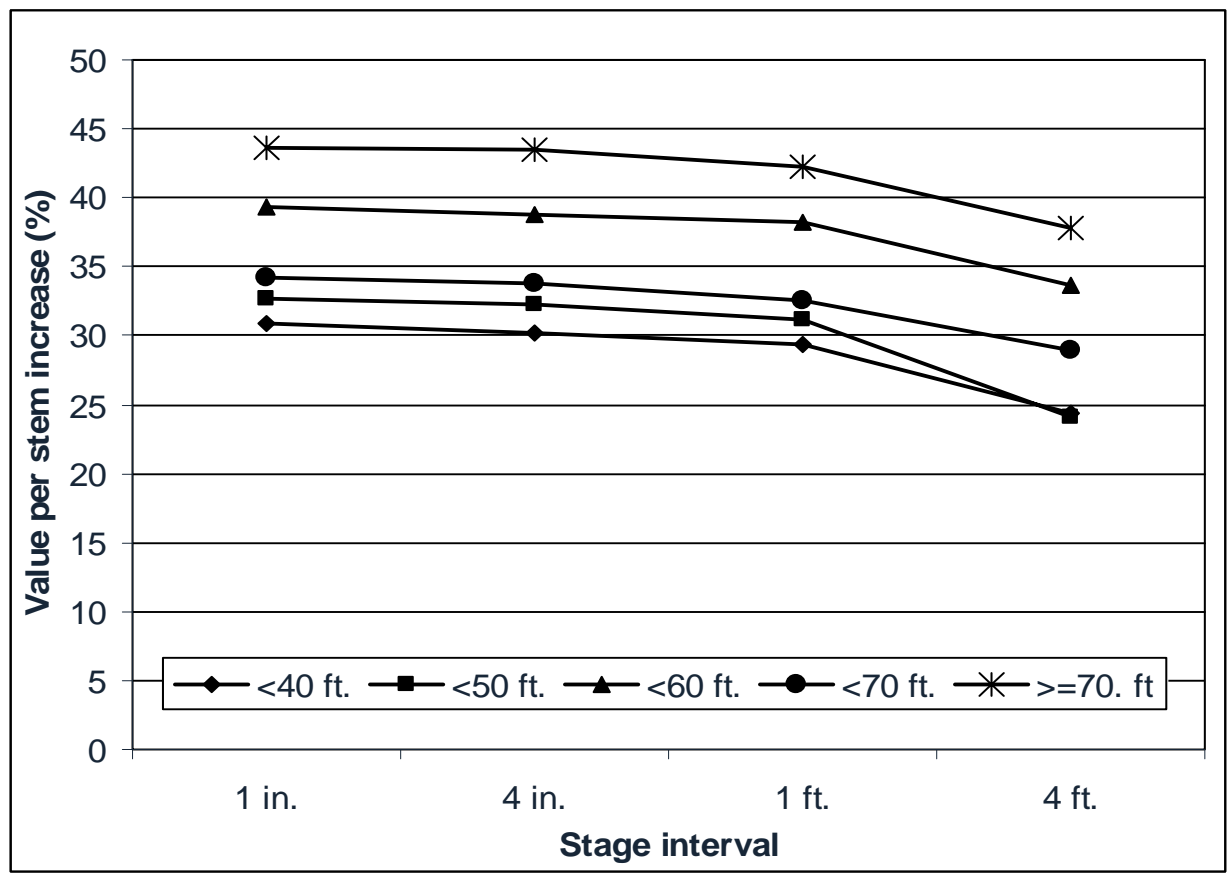

Figure 4.4. Increase of value per stem vs. stage interval by MHT class.

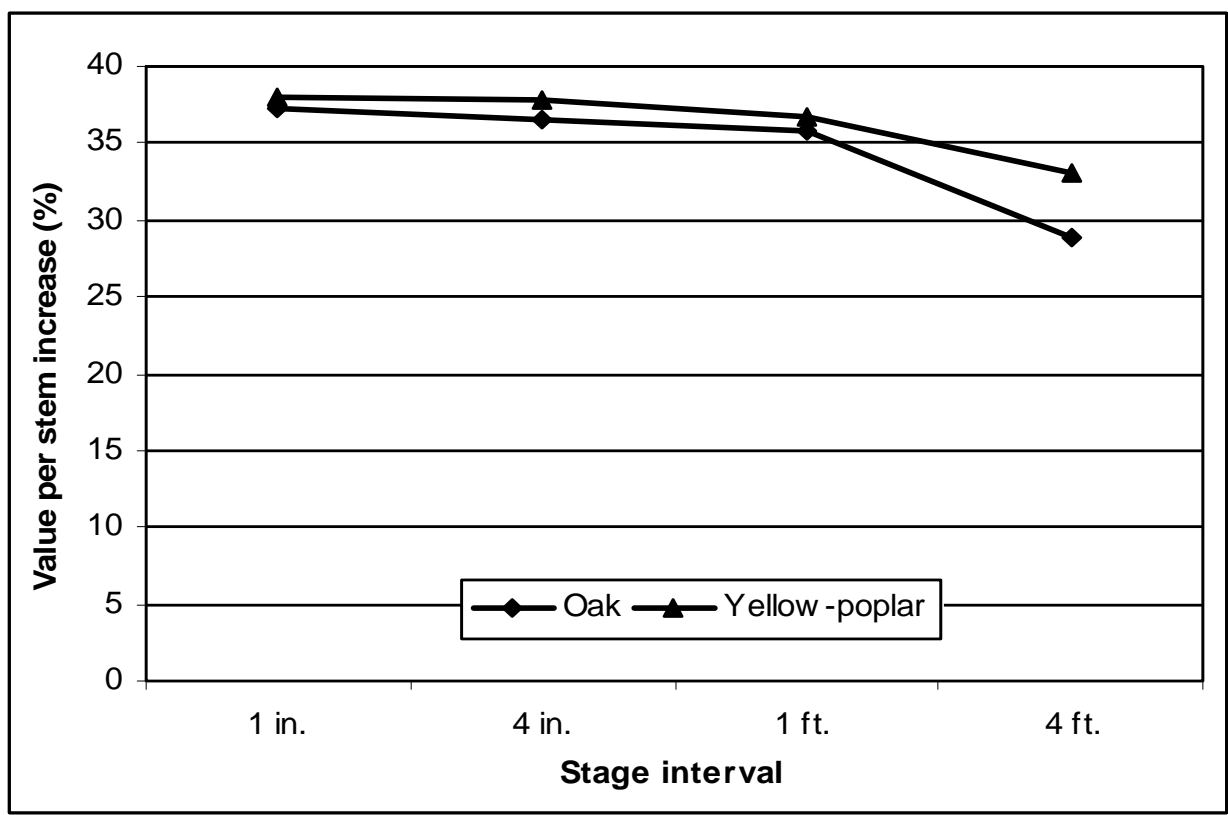

Figure 4.5. Increase of value per stem vs. stage interval by species.

In this study, bucker's experience ranged from 14 years to 20 years and were classified as two groups: $15 \mathrm{yr}$. and $20 \mathrm{yr}$. When comparing optimal bucking with manual bucking based on bucker's experience, optimal bucking could increase higher 
percentage of stem value compared to the manual bucking results made by buckers with 15 years experience than buckers with 20 year experience

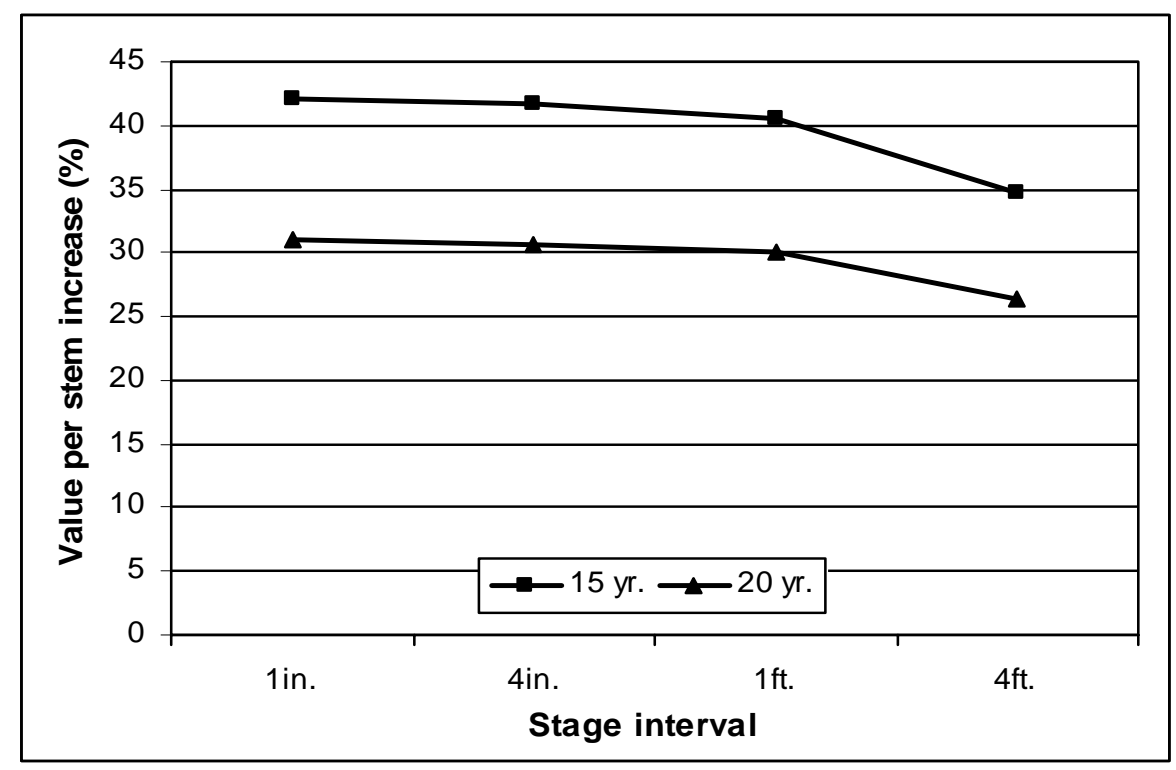

Figure 4.6. Increase of value pre stem vs. stage interval by bucker's experience.

\subsubsection{Comparisons of Significant Differences.}

One tailed t-test was employed to test if the bucking results were significantly different between manual bucking and computer optimal bucking. Let $d_{i}$ represent the difference between average stem values, volumes, value/BF, or utilization rate of optimal bucking and manual bucking for stem $i$. The null hypothesis is that there is no significant difference between computer bucking and manual bucking. The alternative hypothesis is that computer bucking can significantly increase average stem values, volumes, value/BF or utilization rate. Therefore, the null and alternative hypotheses can be expressed as:

$\mathrm{H}_{0}: \bar{d}=0$

$\mathrm{H}_{1}: \bar{d}>0$

and, $d_{i}=V_{i c}-V_{i m}$ 
Where, $V_{i c}$ is average stem value, volume, value/BF or utilization rate for stem $i$ when using optimal bucking. $V_{\text {im }}$ is average stem value, volume, value/BF for stem $i$ when using manual bucking.

Under equal variance assumption, the results indicated that at $\alpha=0.05$ level, optimal bucking could significantly increase the average stem value, stem volume, value/BF and utilization rate compared to manual bucking (Table 4.4).

Table 4.4. One tailed t-test for optimal bucking vs. manual bucking results.

\begin{tabular}{lccccc}
\hline & Method & Variances & DF & T & p \\
\hline Average stem value & Pooled & Equal & 1318 & 3.96 & 0.0001 \\
Average stem volume & Pooled & Equal & 1318 & 2.81 & 0.0025 \\
Value/unit volume & Pooled & Equal & 1318 & 4.97 & 0.0001 \\
Utilization rate & Pooled & Equal & 1318 & 5.44 & 0.0001 \\
\hline
\end{tabular}

Factors that may influence stem value, stem volume and value/BF of manual bucking results include species, DBH, MHT, bucker's experience, number of defects, size of defects, and interactions among species and DBH, species and MHT, species and size of defects, DBH and MHT, and MHT and number of defects. The generic GLM model for estimating stem value, stem volume, or value/BF by manual bucking is expressed as equation (4-1).

$$
\begin{aligned}
& V_{i j k l m n o}=\mu+S P_{i}+D_{j}+H_{k}+B E_{l}+N D_{m}+S D_{n}+ \\
& S P_{i}^{*} D_{j}+S P_{i} * H_{k}+S P_{i} * S D_{n}+D_{j} * H_{k}+H_{k} * N D_{m}+\varepsilon_{i j k l m n o} \\
& \mathrm{i}=1,2 \\
& \mathrm{j}=1,2, \ldots, 4 \\
& \mathrm{k}=1,2, \ldots, 5 \\
& 1=1,2 \\
& \mathrm{~m}=1,2, \ldots, 4
\end{aligned}
$$


$\mathrm{n}=1,2,3$

Where: $V_{i j k l m n o}=$ stem value, stem volume or value/BF of the $\mathrm{o}^{\text {th }}$ stem,

$$
\begin{aligned}
& \mu=\text { mean of stem value, stem volume of value/BF, } \\
& S P_{i}=\text { effect of the } \mathrm{i}^{\text {th }} \text { species, } \\
& D_{j}=\text { effect of the } \mathrm{j}^{\text {th }} \mathrm{DBH}, \\
& H_{k}=\text { effect of the } \mathrm{k}^{\text {th }} \mathrm{MHT}, \\
& B E_{l}=\text { effect of the } \mathrm{1}^{\text {th }} \text { bucker's experience, } \\
& N D_{m}=\text { effect of the } \mathrm{m}^{\text {th }} \text { number of defects, } \\
& S D_{n}=\text { effect of the } \mathrm{n}^{\text {th }} \text { average size of defects, } \\
& \varepsilon_{i j k l m n o}=\text { an error component that represents random variability. }
\end{aligned}
$$

For manual bucking, value of logs bucked per stem was significant different among DBH classes $(\mathrm{F}=100.26 ; \mathrm{df}=3,263 ; \mathrm{p}=0.0001)$, bucker's experience $(\mathrm{F}=24.04$; $\mathrm{df}=1,263 ; \mathrm{p}=0.0001)$, and the interaction among DBH classes and MHT classes $(\mathrm{F}=$ $2.56 ; \mathrm{df}=10,263 ; \mathrm{p}=0.0060)$. Volume per stem for manual bucking was significantly influenced by DBH classes $(\mathrm{F}=103.88 ; \mathrm{df}=3,263 ; \mathrm{p}=0.0001)$, MHT classes $(\mathrm{F}=3.12$; $\mathrm{df}=4,263 ; \mathrm{p}=0.0160)$, bucker's experience $(\mathrm{F}=7.88 ; \mathrm{df}=1,263 ; \mathrm{p}=0.0054)$ and interaction among species and DBH classes $(F=3.05 ; \mathrm{df}=3,263 ; \mathrm{p}=0.0295)$. Value/BF for manual bucking was significantly affected by Species $(\mathrm{F}=14.51 ; \mathrm{df}=$ $1,263 ; \mathrm{p}=0.0002), \mathrm{DBH}$ classes $(\mathrm{F}=17.56 ; \mathrm{df}=3,263 ; \mathrm{p}=0.0001)$, bucker's experience $(\mathrm{F}=136.54 ; \mathrm{df}=1,263 ; \mathrm{p}=0.0001)$, number of defects $(\mathrm{F}=9.11 ; \mathrm{df}=3,263 ; \mathrm{p}=0.0001)$ and interaction between DBH classes and MHT classes $(\mathrm{F}=2.71 ; \mathrm{df}=10,263 ; \mathrm{p}=$ 0.0037) (Table 4.5). 
Table 4.5. Means and significance levels of bucking results by manual bucking. ${ }^{\text {a }}$

\begin{tabular}{|c|c|c|c|}
\hline & Value/stem (\$) & Volume/stem (BF) & $\begin{array}{l}\text { Value/unit volume } \\
\qquad \$(B F)\end{array}$ \\
\hline \multicolumn{4}{|c|}{ DBH (in.) } \\
\hline$<15$ & $14.462 \mathrm{~d}$ & $62.34 \mathrm{~d}$ & $0.20030 \mathrm{c}$ \\
\hline $15-20$ & $54.765 \mathrm{c}$ & $178.72 \mathrm{c}$ & $0.30157 \mathrm{~b}$ \\
\hline $20-25$ & $139.249 \mathrm{~b}$ & $342.20 \mathrm{~b}$ & $0.40837 \mathrm{a}$ \\
\hline$>=25$ & $266.008 \mathrm{a}$ & $669.11 \mathrm{a}$ & $0.40965 \mathrm{a}$ \\
\hline \multicolumn{4}{|c|}{ MHT (ft.) } \\
\hline$<40$ & $27.196 \mathrm{~d}$ & $88.43 \mathrm{e}$ & $0.28096 \mathrm{~b}$ \\
\hline $40-50$ & $49.305 \mathrm{c}$ & $144.10 \mathrm{~d}$ & $0.30365 \mathrm{ab}$ \\
\hline $50-60$ & $75.302 b$ & $202.51 \mathrm{c}$ & $0.32925 \mathrm{a}$ \\
\hline $60-70$ & $81.586 \mathrm{~b}$ & $237.70 \mathrm{~b}$ & $0.30223 \mathrm{ab}$ \\
\hline$>=70$ & $100.701 \mathrm{a}$ & $306.22 \mathrm{a}$ & $0.28175 \mathrm{~b}$ \\
\hline \multicolumn{4}{|c|}{ Species } \\
\hline Yellow-poplar & $76.089 \mathrm{a}$ & $238.255 \mathrm{a}$ & $0.265849 \mathrm{~b}$ \\
\hline Oak & $61.322 \mathrm{~b}$ & $156.605 \mathrm{~b}$ & $0.349692 \mathrm{a}$ \\
\hline \multicolumn{4}{|c|}{ Number of defects } \\
\hline$<5$ & $78.098 \mathrm{ab}$ & $208.22 \mathrm{~b}$ & $0.32515 \mathrm{a}$ \\
\hline $5-10$ & $58.219 \mathrm{c}$ & $167.61 \mathrm{c}$ & $0.29942 \mathrm{ab}$ \\
\hline $10-15$ & $88.702 \mathrm{a}$ & $263.46 \mathrm{a}$ & $0.30885 \mathrm{a}$ \\
\hline$>=15$ & $71.900 \mathrm{bc}$ & $236.08 \mathrm{ab}$ & $0.27518 \mathrm{~b}$ \\
\hline \multicolumn{4}{|c|}{ Size of defects (in.) } \\
\hline$<5$ & $37.211 \mathrm{c}$ & $135.88 \mathrm{~b}$ & $0.24405 \mathrm{~b}$ \\
\hline $5-10$ & $90.538 \mathrm{~b}$ & $246.09 \mathrm{a}$ & $0.34440 \mathrm{a}$ \\
\hline$>=10$ & $111.368 \mathrm{a}$ & $259.22 \mathrm{a}$ & $0.35296 \mathrm{a}$ \\
\hline \multicolumn{4}{|c|}{ Experience (yr.) } \\
\hline 15 & $62.321 \mathrm{~b}$ & $186.449 \mathrm{~b}$ & $0.285539 \mathrm{~b}$ \\
\hline 20 & $83.656 \mathrm{a}$ & $231.455 \mathrm{a}$ & $0.339847 \mathrm{a}$ \\
\hline
\end{tabular}

${ }^{a}$ Means with the same capital letter in a column of the same group are not significantly different at the 5 percent level with Duncan's Multiple-Range Test.

For optimal bucking, stem value, stem volume and value/BF could be influenced by species, DBH, MHT, stage interval, number of defects, size of defects and interactions among species and DBH, species and MHT, species and size of defects, DBH and MHT, and MHT and number of defects. The generic GLM model for estimating stem value, stem volume, or value/BF obtained from optimal bucking is expressed as equation (4-2). 


$$
\begin{aligned}
& V_{i j k l m n o}=\mu+S P_{i}+D_{j}+H_{k}+S I_{l}+N D_{m}+S D_{n}+ \\
& S P_{i} * D_{j}+S P_{i} * H_{k}+S P_{i} * S D_{n}+D_{j} * H_{k}+H_{k} * N D_{m}+\varepsilon_{i j k l m n o} \\
& \mathrm{i}=1,2 \\
& \mathrm{j}=1,2, \ldots, 4 \\
& \mathrm{k}=1,2, \ldots, 5 \\
& 1=1,2, \ldots, 4 \\
& \mathrm{~m}=1,2, \ldots, 4 \\
& \mathrm{n}=1,2,3
\end{aligned}
$$

Where: $V_{i j k l m n o}=$ stem value, stem volume or value/BF of the $o^{\text {th }}$ stem,

$$
\begin{aligned}
& \mu=\text { mean of stem value, stem volume of value/BF, } \\
& S P_{i}=\text { effect of the } \mathrm{i}^{\text {th }} \text { species, } \\
& D_{j}=\text { effect of the } \mathrm{j}^{\text {th }} \mathrm{DBH}, \\
& H_{k}=\text { effect of the } \mathrm{k}^{\text {th }} \mathrm{MHT}, \\
& S I_{l}=\text { effect of the } 1^{\text {th }} \text { stage interval, } \\
& N D_{m}=\text { effect of the } \mathrm{m}^{\text {th }} \text { number of defects, } \\
& S D_{n}=\text { effect of the } \mathrm{n}^{\text {th }} \text { average size of defects, } \\
& \varepsilon_{i j k l m n o}=\text { an error component that represents random variability. }
\end{aligned}
$$

Value per stem obtained from optimal bucking was significantly affected by DBH classes $(F=439.51 ; \mathrm{df}=3,1055 ; \mathrm{p}=0.0001)$, MHT classes $(\mathrm{F}=7.90 ; \mathrm{df}=4,1055 ; \mathrm{p}=$ $0.0001)$, number of defects $(F=4.79 ; \mathrm{df}=3,1055 ; \mathrm{p}=0.0026)$, and interactions between DBH classes and MHT classes $(\mathrm{F}=18.91 ; \mathrm{df}=10,1055 ; \mathrm{p}=0.0001)$, species and size of defects $(F=6.05 ; \mathrm{df}=2,1055 ; \mathrm{p}=0.0024)$, and MHT classes and number of defects $(\mathrm{F}=$ 
$4.89 ; \mathrm{df}=11,1055 ; \mathrm{p}=0.0001)$. Volume per stem by optimal bucking was significantly affect by DBH classes $(F=446.32 ; \mathrm{df}=3,1055 ; \mathrm{p}=0.0001)$, MHT classes $(\mathrm{F}=17.90 ; \mathrm{df}$ $=4,1055 ; \mathrm{p}=0.0001)$, number of defects $(\mathrm{F}=7.92 ; \mathrm{df}=3,1055 ; \mathrm{p}=0.0001)$, interactions between DBH classes and MHT classes $(F=10.45 ; \mathrm{df}=10,1055 ; \mathrm{p}=0.0001)$, species and DBH classes $(\mathrm{F}=10.17 ; \mathrm{df}=3,1055 ; \mathrm{p}=0.0001)$, species and MHT classes $(\mathrm{F}=$ 4.96; $\mathrm{df}=3,1055 ; \mathrm{p}=0.0020)$, and MHT classes and number of defects $(\mathrm{F}=7.01 ; \mathrm{df}=$ $11,1055 ; \mathrm{p}=0.0001)$. Value/BF for optimal bucking was significantly affected by species $(\mathrm{F}=35.42 ; \mathrm{df}=1,1055 ; \mathrm{p}=0.0001), \mathrm{DBH}$ classes $(\mathrm{F}=125.65 ; \mathrm{df}=3,1055 ; \mathrm{p}=$ $0.0001)$, MHT classes $(\mathrm{F}=10.90 ; \mathrm{df}=4,1055 ; \mathrm{p}=0.0001)$, number of defects $(\mathrm{F}=12.13$; $\mathrm{df}=3,1055 ; \mathrm{p}=0.0001)$, interactions between species and size of defects $(\mathrm{F}=4.37 ; \mathrm{df}=$ $2,1055 ; \mathrm{p}=0.0129), \mathrm{DBH}$ classes and MHT classes $(\mathrm{F}=21.55 ; \mathrm{df}=10,1055 ; \mathrm{p}=$ $0.0001)$, species and DBH classes ( $\mathrm{F}=18.64 ; \mathrm{df}=3,1105 ; \mathrm{p}=0.0001)$, species and MHT classes $(\mathrm{F}=4.11 ; \mathrm{df}=3,1055 ; \mathrm{p}=0.0066)$, and MHT classes and number of defects $(\mathrm{F}=$ 4.54; $\mathrm{df}=11,1055 ; \mathrm{p}=0.0001)$ (Table 4.6). Compared to manual bucking, more factors showed significant effects on bucking results, which indicated that optimal bucking could evaluate factors that might affect bucking results more accurately than manual bucking. As stage interval decreased, value per stem, volume per stem and value/BF increased, but these increases were not statistically significant $(F=0.50 ; \mathrm{df}=3,1055 ; \mathrm{p}=0.6802, \mathrm{~F}=$ $0.01 ; \mathrm{df}=3,1055 ; \mathrm{p}=0.9983$, and $\mathrm{F}=1.49 ; \mathrm{df}=3,1055 ; \mathrm{p}=0.2156)$. 
Table 4.6. Means and significance levels of bucking results by optimal bucking. ${ }^{\text {a }}$

\begin{tabular}{lccc}
\hline & Value/stem (\$) & Volume/stem (BF) & $\begin{array}{c}\text { Value/unit volume } \\
(\$ / B F)\end{array}$ \\
\hline & & DBH (in.) & \\
$<15$ & $20.935 \mathrm{~d}$ & $84.20 \mathrm{~d}$ & $0.22898 \mathrm{~d}$ \\
$15-20$ & $71.277 \mathrm{c}$ & $208.62 \mathrm{c}$ & $0.33779 \mathrm{c}$ \\
$20-25$ & $191.363 \mathrm{~b}$ & $388.22 \mathrm{~b}$ & $0.49855 \mathrm{~b}$ \\
$>=25$ & $287.625 \mathrm{a}$ & $742.83 \mathrm{a}$ & $0.53871 \mathrm{a}$ \\
& & MHT (ft.) & \\
$<40$ & $34.993 \mathrm{~d}$ & $103.489 \mathrm{e}$ & $0.316145 \mathrm{c}$ \\
$40-50$ & $64.112 \mathrm{c}$ & $163.948 \mathrm{~d}$ & $0.341028 \mathrm{~b}$ \\
$50-60$ & $103.532 \mathrm{~b}$ & $232.812 \mathrm{c}$ & $0.395252 \mathrm{a}$ \\
$60-70$ & $107.998 \mathrm{~b}$ & $275.575 \mathrm{~b}$ & $0.346564 \mathrm{~b}$ \\
$>=70$ & $142.814 \mathrm{a}$ & $265.531 \mathrm{a}$ & $0.333095 \mathrm{bc}$ \\
& & Species & \\
Yellow-poplar & $103.775 \mathrm{a}$ & $280.971 \mathrm{a}$ & $0.309006 \mathrm{~b}$ \\
Oak & $82.532 \mathrm{~b}$ & $177.193 \mathrm{~b}$ & $0.403914 \mathrm{a}$ \\
& & Number of defects & \\
$<5$ & $101.995 \mathrm{~b}$ & $238.139 \mathrm{c}$ & $0.379184 \mathrm{a}$ \\
$5-10$ & $78.221 \mathrm{c}$ & $195.815 \mathrm{~d}$ & $0.341902 \mathrm{~b}$ \\
$10-15$ & $124.675 \mathrm{a}$ & $305.768 \mathrm{a}$ & $0.364941 \mathrm{a}$ \\
$>=15$ & $99.085 \mathrm{~b}$ & $277.469 \mathrm{~b}$ & $0.326012 \mathrm{~b}$ \\
& & Size of defects (in.) & \\
$<5$ & $50.651 \mathrm{~b}$ & $164.45 \mathrm{~b}$ & $0.27968 \mathrm{~b}$ \\
$5-10$ & $123.296 \mathrm{a}$ & $281.64 \mathrm{a}$ & $0.40123 \mathrm{a}$ \\
$>=10$ & $141.543 \mathrm{a}$ & $296.08 \mathrm{a}$ & $0.40950 \mathrm{a}$ \\
& $95.605 \mathrm{a}$ & $233.750 \mathrm{a}$ & $0.356611 \mathrm{a}$ \\
1 in. & $95.315 \mathrm{a}$ & $234.170 \mathrm{a}$ & $0.355258 \mathrm{a}$ \\
4 in. & $94.654 \mathrm{a}$ & $234.894 \mathrm{a}$ & $0.352650 \mathrm{a}$ \\
$1 \mathrm{ft}$. & $91.226 \mathrm{a}$ & $233.955 \mathrm{a}$ & $0.342628 \mathrm{a}$ \\
$4 \mathrm{ft}$. & & Stage interval & \\
\hline & & & \\
& & &
\end{tabular}

${ }^{a}$ Means with the same capital letter in a column of the same group are not significantly different at the 5 percent level with Duncan's Multiple-Range Test.

Combining equation (4-1) and (4-2), the generic GLM model for stem value, stem volume or value/BF for bucking a stem can be expressed as equation (4-3).

$$
\begin{aligned}
& V_{i j k l m n o}=\mu+B K_{i}+S P_{j}+D_{k}+H_{l}+N D_{m}+S D_{n}+ \\
& S P_{j} * D_{k}+S P_{j} * H_{l}+S P_{j} * S D_{n}+D_{k} * H_{l}+H_{l} * N D_{m}+\varepsilon_{i j k l m n o}
\end{aligned}
$$




$$
\begin{aligned}
& i=1,2 \\
& j=1,2 \\
& k=1,2, \ldots, 4 \\
& 1=1,2, \ldots, 5 \\
& m=1,2, \ldots, 4 \\
& n=1,2,3
\end{aligned}
$$

Where: $V_{i j k l m n o}=$ stem value, stem volume or value/BF of the $o^{\text {th }}$ stem,

$\mu=$ mean of stem value, stem volume of value $/ \mathrm{BF}$, $B K_{i}=$ effect of the $\mathrm{i}^{\text {th }}$ bucking method, $S P_{j}=$ effect of the $\mathrm{j}^{\text {th }}$ species,

$D_{k}=$ effect of the $\mathrm{k}^{\text {th }} \mathrm{DBH}$, $H_{l}=$ effect of the $1^{\text {th }}$ MHT, $N D_{m}=$ effect of the $\mathrm{m}^{\text {th }}$ number of defects, $S D_{n}=$ effect of the $\mathrm{n}^{\text {th }}$ average size of defects, $\varepsilon_{i j k l m n o}=$ an error component that represents random variability. 
Table 4.7. Means and significance levels of generic bucking results. ${ }^{a}$

\begin{tabular}{|c|c|c|c|}
\hline & Value/stem (\$) & Volume/stem (BF) & $\begin{array}{l}\text { Value/ unit volume } \\
\text { (\$/BF) }\end{array}$ \\
\hline \multicolumn{4}{|c|}{ Bucking method } \\
\hline Manual bucking & $69.433 \mathrm{~b}$ & $201.451 \mathrm{~b}$ & $0.303642 \mathrm{~b}$ \\
\hline Optimal bucking & $94.200 \mathrm{a}$ & $234.192 \mathrm{a}$ & $0.351787 \mathrm{a}$ \\
\hline \multicolumn{4}{|c|}{ DBH (in.) } \\
\hline$<15$ & $19.640 \mathrm{~d}$ & $79.831 \mathrm{~d}$ & $0.22324 \mathrm{~d}$ \\
\hline $15-20$ & $67.975 \mathrm{c}$ & $202.638 \mathrm{c}$ & $0.33054 \mathrm{c}$ \\
\hline $20-25$ & $180.940 \mathrm{~b}$ & $379.016 b$ & $0.48051 \mathrm{~b}$ \\
\hline$>=25$ & $363.301 \mathrm{a}$ & $728.089 \mathrm{a}$ & $0.51290 \mathrm{a}$ \\
\hline \multicolumn{4}{|c|}{ MHT (ft.) } \\
\hline$<40$ & $33.434 \mathrm{~d}$ & $100.478 \mathrm{e}$ & $0.309108 \mathrm{c}$ \\
\hline $40-50$ & $61.150 \mathrm{c}$ & $159.979 \mathrm{~d}$ & $0.333552 \mathrm{~b}$ \\
\hline $50-60$ & $97.886 \mathrm{~b}$ & $226.751 \mathrm{c}$ & $0.382051 \mathrm{a}$ \\
\hline $60-70$ & $102.716 \mathrm{~b}$ & $268.000 \mathrm{~b}$ & $0.337698 \mathrm{~b}$ \\
\hline$>=70$ & $134.391 \mathrm{a}$ & $353.669 \mathrm{a}$ & $0.322825 \mathrm{bc}$ \\
\hline \multicolumn{4}{|c|}{ Number of defects } \\
\hline$<5$ & $97.216 \mathrm{~b}$ & $232.156 \mathrm{c}$ & $0.368378 \mathrm{a}$ \\
\hline $5-10$ & $74.221 \mathrm{c}$ & $190174 \mathrm{~d}$ & $0.333406 \mathrm{~b}$ \\
\hline $10-15$ & $117.481 \mathrm{a}$ & $297.305 \mathrm{a}$ & $0.353724 \mathrm{a}$ \\
\hline$>=15$ & $93.648 \mathrm{~b}$ & $269.192 \mathrm{~b}$ & $0.315846 \mathrm{c}$ \\
\hline \multicolumn{4}{|c|}{ Size of defects (in.) } \\
\hline$<5$ & $47.963 \mathrm{c}$ & $158.739 \mathrm{~b}$ & $0.27255 \mathrm{~b}$ \\
\hline $5-10$ & $116.745 \mathrm{~b}$ & $274.529 \mathrm{a}$ & $0.38986 \mathrm{a}$ \\
\hline$>=10$ & $135.508 \mathrm{a}$ & $288.711 \mathrm{a}$ & $0.39819 \mathrm{a}$ \\
\hline \multicolumn{4}{|c|}{ Species } \\
\hline Yellow-poplar & $98.238 \mathrm{a}$ & $272.428 \mathrm{a}$ & $0.300375 \mathrm{~b}$ \\
\hline Oak & $78.290 \mathrm{~b}$ & $173.076 \mathrm{~b}$ & $0.393070 \mathrm{a}$ \\
\hline
\end{tabular}

${ }^{\mathrm{a}}$ Means with the same capital letter in a column of the same group are not significantly different at the 5 percent level with Duncan's Multiple-Range Test.

Value per stem gain by a generic bucking method could be significantly different among bucking method $(\mathrm{F}=63.28 ; \mathrm{df}=1,1319 ; \mathrm{p}=0.0001)$, number of defects $(\mathrm{F}=5.57$; $\mathrm{df}=3,1319 ; \mathrm{p}=0.0008), \mathrm{DBH}$ classes $(\mathrm{F}=503.16 ; \mathrm{df}=3,1319 ; \mathrm{p}=0.0001)$, MHT classes $(\mathrm{F}=7.97 ; \mathrm{df}=4,1319 ; \mathrm{p}=0.0001)$, interactions between species and size of 
defects, $(\mathrm{F}=7.78 ; \mathrm{df}=2,1319 ; \mathrm{p}=0.0004)$, DBH classes and MHT classes $(\mathrm{F}=19.86$; $\mathrm{df}$ $=10,1319 ; \mathrm{p}=0.0001)$, species and MHT classes $(\mathrm{F}=2.71 ; \mathrm{df}=6,1319 ; \mathrm{p}=0.0439)$ and MHT classes and number of defects $(\mathrm{F}=5.97 ; \mathrm{df}=11,1319 ; \mathrm{p}=0.0001)$. Volume per stem obtained from a generic bucking method was significantly affected by bucking method $(F=40.33 ; \mathrm{df}=1,1319 ; \mathrm{p}=0.0001), \mathrm{DBH}$ classes $(\mathrm{F}=557.96 ; \mathrm{df}=3,1319 ; \mathrm{p}=$ $0.0001)$, MHT classes $(F=20.95 ; \mathrm{df}=4,1319 ; \mathrm{p}=0.0001)$, number of defects $(\mathrm{F}=9.95$; $\mathrm{df}=3,1319 ; \mathrm{p}=0.0001)$ and interactions between species and size of defects $(\mathrm{F}=3.86 ; \mathrm{df}$ $=2,1319 ; \mathrm{p}=0.0213)$, DBH classes and MHT classes $(\mathrm{F}=12.28 ; \mathrm{df}=10,1319 ; \mathrm{p}=$ $0.0001)$, species and DBH classes $(\mathrm{F}=13.40 ; \mathrm{df}=3,1319 ; \mathrm{p}=0.0001)$, species and MHT classes $(\mathrm{F}=6.28 ; \mathrm{df}=3,1319 ; \mathrm{p}=0.0003)$ and MHT classes and number of defects $(\mathrm{F}=$ $8.81 ; \mathrm{df}=11,1319 ; \mathrm{p}=0.0001)$. Factors having a significant affect on value/BF by generic bucking include bucking method $(\mathrm{F}=70.38 ; \mathrm{df}=1,1319 ; \mathrm{p}=0.0001)$, species $(\mathrm{F}$ $=46.37 ; \mathrm{df}=1,1319 ; \mathrm{p}=0.0001), \mathrm{DBH}$ classes $(\mathrm{F}=137.42 ; \mathrm{df}=3,1319 ; \mathrm{p}=0.0001)$ MHT classes $(F=10.90 ; \mathrm{df}=4,1319 ; \mathrm{p}=0.0001)$, number of defects $(\mathrm{F}=15.88 ; \mathrm{df}=$ $3,1319 ; \mathrm{p}=0.0001)$, size of defects $(\mathrm{F}=3.09 ; \mathrm{df}=2,1319 ; \mathrm{p}=0.0457)$, interactions between species and size of defects $(\mathrm{F}=6.03 ; \mathrm{df}=2,1319 ; \mathrm{p}=0.0025), \mathrm{DBH}$ classes and MHT classes $(\mathrm{F}=23.03 ; \mathrm{df}=10,1319 ; \mathrm{p}=0.0001)$, species and DBH classes $(\mathrm{F}=19.15$; $\mathrm{df}=3,1319 ; \mathrm{p}=0.0001)$, species and MHT classes $(\mathrm{F}=4.63 ; \mathrm{df}=3,1319 ; \mathrm{p}=0.0032)$ and MHT classes and number of defects $(\mathrm{F}=6.10 ; \mathrm{df}=11,1319 ; \mathrm{p}=0.0001)($ Table 4.7). 


\section{CHAPTER 5: CONCLUSIONS AND DISCUSSION}

The optimal bucking system developed in this study adopted component object modeling (COM) techniques with objected-oriented programming and 3-D graphs. The system can be installed on a handheld field PC or a desktop PC located in a centralized log yard to improve central Appalachian hardwood utilization. It can be used as a training tool for students or loggers.

A network analysis algorithm was employed to achieve the maximum total log value per stem. The selection of a stage interval is a key factor that affects the system execution time and final bucking results. The smaller the stage interval, the longer it will take to achieve the optimal bucking solution. Balancing the time of finding the optimal results using an appropriate stage interval could enhance the application of this bucking system.

Applying this system on 264 tree stems of 6 hardwood species and comparing the results obtained with manual bucking results, showed that optimal can increase stem value by $31.39 \%$ to $37.69 \%$. The total volume of logs bucked per stem could be increased by $16.03 \%$ to $16.60 \%$. Value/unit volume and stem utilization rate were also increased by 13.13 to $18.67 \%$ and 10.11 to $11.23 \%$. System execution time was significantly affected by stage interval and number of defects. When stage interval decreased from 4-foot to 1-foot, 4-inch, and 1-inch, system execution time increased 13, 108, and 1702 times, respectively.

Results of a one tailed t-test ( $\alpha=0.05$ ) indicated that value per stem, volume per stem, value/BF or utilization rate was significantly increased over manual bucking. Increased volume and utilization rate per stem showed that optimal bucking could use 
stem resources more efficiently. Optimal bucking yielded higher value/unit volume than manual bucking, which indicated that optimal bucking could produce logs with more valuable grades than manual bucking.

Analysis of variance (ANOVA) indicated that manual bucking results were affected by bucker's experience and the physical dimension of bucked stems. The results also indicated that DBH classes, bucker's experience and interaction among DBH classes and MHT classes have significant effect on value per stem and value per unit volume. DBH classes and MHT classes, bucker's experience and interaction among DBH classes and MHT classes could significantly affect volume per stem. Value/BF was significantly affected by species, DBH classes, bucker's experience, number of defects and interaction between DBH classes and MHT classes.

In addition to stem dimension factors, the number of defects per stem and average size of defects also significantly affected the value of logs bucked per stem, volume per stem and value/BF by optimal bucking. It simply implies that computer optimal bucking usually checks the detailed defects information before yielding a bucking decision. When comparing bucking results from optimal bucking and manual bucking methods by DBH and MHT classes, it showed that the bigger DBH and MHT, the higher percentage of value increase could be achieved. This indicated that optimal bucking could achieve more value on larger tree stem.

In this study, only two major species groups, yellow-poplar and oaks, were compared. It showed that optimal bucking could slightly increase higher percentage of stem value when bucking yellow-poplar when compared with oaks. This is probably due 
to oaks having more defects and irregular shapes. More species, specifically valuable species, will be tested by using the system.

All buckers observed in this study had 14 to 20 years of working experience. Comparing manual bucking results by different experience groups to computer bucking result, it showed that optimal bucking could slightly increase higher percentage of stem value increase of 15 year experience group than 20 year experience group.

The stem shape data were measured at outside bark diameter. Outside bark diameters were currently converted to inside bark diameter for each species using a constant ratio. More accurate shape estimates should be used in the system to achieve more accurate optimal bucking results. Currently, the shapes and defects data need to be measured manually in the field, which is a time consuming and tedious. Using electronic devices to automatically measure and collect these data will facilitate this optimal bucking system. Comparisons between this optimal bucking system and HW-BUCK will help us to evaluate this system and make necessary system improvements for future field applications. 


\section{LITERATURE CITED}

Arce, J.E., C. Celso, R.S. Carlos, and F.F. Afonso, 2002. A forest-level bucking optimization system that considers customer's demand and transportation costs. Forest Science. 48(3):492-503.

Aris R. 1964. Discrete Dynamic Programming. Blaisdell Publishing Co., N. Y.

Avery, T.E. and H.E. Burkhart. 2001. Forest Measurements, Fourth edition. McGrawHill INC., San Francisco, California. 408 pp.

Bellman, P.E. and S.E. Dreyfus. 1962. Applied Dynamic Programming. Princeton University Press, Princeton, N. J.

Briggs, D.G. 1980. A dynamic programming approach to optimized stem conversion. Ph.D. Diss., Coll. of For. Res., Univ. of Washington. Seattle. 393p.

Bobrowski, P.M. 1990. Branch-and-bound strategies for the log bucking problem. Decision Sciences. 21:1-13.

Bobrowski, P.M. 1994a. The effects of modeling on log bucking solution techniques. J. Opl. Res. Soc. 45(6):624-634.

Bobrowski, P.M. 1994b. The log bucking problem: A comparison of dynamic programming versus branch and bound. European Journal of Operational Research. 72: 495-508.

Boston, K. and G. Murphy. 2003. Value recovery from two mechanized bucking operations in the Southeastern United States, Southern Journal of Applied Forestry. 27(4):259-263.

Clemmons, J.W. 1966. New techniques in individual tree description for the basis of economic decision making. Proc. SAF annual meeting, Seattle, Washington.

Dykstra, D.P. 1984. Mathematical programming for natural resource management. McGraw-Hill INC., N.Y. p: 299-305.

Eng. G. 1982. A methodology for forest outturn assessment and optimal tree bucking. M. Sc. Unpublished Thesis, University of Canterbury. Christchurch, New Zealand.

Eng G. and H.G. Daellenbach. 1985. Forest outturn optimization by Dantzig-Wolfe decomposition and dynamic programming column generation. Operations Research. 33(2): 459-464.

Eng G., H.G. Daellenbach, and A.G.D. Whyte. 1986. Bucking tree-length stems optimally. Canadian Journal of Forest Resources. 16: 1030-1035. 
Epstein, R., R. Morales, J. Seron, and A. Weintraub. 1999. Use of OP systems in the Chilean Forest Industries. Interfaces. 29(1):7-29.

Faaland, B. and D. Briggs. 1984. Log bucking and lumber manufacturing using dynamic programming. Management Science. 30(2):245-257.

Forster, R.B. and J.C. Callahan. 1968. Allocating Indian hardwood timber in multiple product situations. Research Bulletin 843. Purdue University.

Frayer, W.E., J.B. Pickens and J.E. Engel. 1995. HW-BUCK: A computer game to help $\log$ buckers improve value recovery. Proceedings of the $23^{\text {rd }}$ Annual Hardwood Symposium. p37-44.

Garland, J., J. Sessions, and E. Olsen. 1989. Manufacturing logs with computer-aided bucking at the stump. Forest Products Journal. 39(3):62-66.

Geerts, J.M.P., and A.A. Twaddle. 1985. A method to access log value loss caused by cross-cutting practice on the skidsite. N. Z. Journal of Forestry. 29(2): 173-184.

Harrison, C.W., H. E. Burkhart, T.E. Burk, and D.E. Beck. 1986. Growth and yield of Appalachian mixed hardwoods after thinning. Virginia Polytechnic Institute and Stage University. Blacksburg, Virginia. pp 19.

Kivinen, V.P. and J. Uusitalo. 2002. Applying fuzzy logic to tree bucking control. Forest Science. 48(4):673-684.

Kivinen, V.P. 2004. A genetic algorithm approach to tree bucking optimization. Forest Science. 50(5):696-710.

Laroze, A.J. and B.J. Greber. 1997. Using Tabu Search to generate stand level, rulebased bucking patterns. Forest Science. 43(2):157-169.

Laroze, A.J. 1999. A linear programming, Tabu Search method for solving forest-level bucking optimization problems. Forest Science. 45(1):108-116.

Lawrence, M. 1986. Optimal bucking: A review of the literature. IEA/Bioenergy project CPC-9, Report No. 1.

Lembersky, M.R. and U.H. Chi. 1984. "Decision simulators" speed implementation and improve operations. Interfaces. 14(4):1-15.

Lembersky, M.R. and U.H. Chi. 1986. Weyerhaeuser decision simulator improves timber profits. Interfaces. 16(1):6-15. 
Mendoza, G.A. and B.B. Bare. 1986. A two-stage decision model for log bucking and allocation. Forest Products Journal. 36(10): 70-75.

Milauskas, S. and J. Wang. 2006. West Virginia logger characteristics. Forest Products Journal. 56(2):19-24.

Näsburg, M. 1985. Mathematical programming models for optimal log bucking. Linkoping University. Dissertation No. 132.

Näsberg, M. 1986. Two tools for marking for bucking analysis. OR Models on Microcomputers. p:23-33.

Olsen, E., S. Pilkerton, J. Garland, and J. Sessions. 1991. Computer aided bucking on a merchandized harvester. Journal of Forest Engineering. 2:25-32.

Pnevmaticos, S.M., and S.H. Mann. 1972. Dynamic programming in tree bucking. Forest Products Journal. 22(2): 26-30.

Pickens, J.B., A. Lee, and G. W. Lyon. 1992. Optimal bucking of northern hardwoods. Northern Journal of Applied Forest. 9:149-152.

Pickens, J.B., A.S. Throop, and J. O. Frendewey. 1997. Choosing prices to optimally bucking hardwood logs with multiple log-length demand restrictions. Forest Science. 43(3):403-413.

Sarrett, W. 1998. Visual C++ database programming tutorial, Wrox Press Ltd. Birmingham. 235pp.

Sessions, J. 1988. Making better tree-bucking decisions in the woods. Journal of Forestry. 10: 43-45.

Sessions, J., J. Garland, and E. Olsen. 1989a. Testing computer-aided bucking at the stump. Journal of Forestry, 87(4):43-45.

Sessions, J., E. Olsen, and J. Garland. 1989b. Tree bucking for optimal stand value with $\log$ allocation constraints. Forest Science. 35(1): 271-276.

Smith, G.W., and G. Harrell. 1961. Linear programming in log production. Forest Products Journal. 11(1):8-11.

Sphar, C. 1999. Learn Microsoft Visual C++6.0 Now. Microsoft Press. WA. 637pp.

Twaddle, A. A. and C. J. Goulding. 1989. Improving profitability by optimizing logmaking. New Zealand Journal of Forestry 34 (1): 17-23. 
Ullman, J. and J. Widow. 1997. A first course in database systems. Prentice Hall. Upper Saddle River, New Jersey.

Wang, J., C. LeDoux, and, J. McNeel. 2004, Optimal tree-stem bucking of northeastern species of China. Forest Products Journal. 52(2):45-52.

Wang, J. and S. Xu. 1990. Dynamic programming and networking analysis models and their applications in optimal tree-stem bucking. Forest Logging Sci. (3):24-31.

Wang, J., S. Grushecky, Y. Li, and J. McNeel. 2006. Hardwood log merchandising and bucking practices in West Virginia. IN: Proceedings of the $15^{\text {th }}$ Central Hardwood Forest Conference, Knoxville, TN. Feb. 28 - March 1, 2006.

Woo, M., J. Neider, T. Davis, D. Shreiner, 2000, OpenGL programming guide: the official guide to learning OpenGL, Version 1.2. Addison-Wesley, Reading, MA. 730 pp. 


\section{APPENDIX A: USER'S MANUAL}

\section{A.1 System Requirements}

The recommended system configuration for this optimal bucking system is Microsoft Windows XP or later version, with Pentium IV processor and 512 megabytes (MB) of RAM. Table A.1 lists the detailed minimum requirements of computer for running this system.

Table A.1. System requirements.

\begin{tabular}{ll}
\hline Item & Requirements \\
\hline Processor & Intel Pentium IV processor or later \\
Operating System & Microsoft Windows XP or later version \\
Memory & 512 MB RAM \\
Hard Disk & 100 MB of free space \\
Drive & CD-ROM drive \\
Display & Super VGA $(800 \times 600)$ with 256 colors \\
Peripherals & Microsoft Mouse or compatible pointing device \\
\hline
\end{tabular}

\section{A.2 System Installation}

This optimal bucking system is compiled in a release version, and no setup is required. Insert the system $\mathrm{CD}$ to $\mathrm{CD}-\mathrm{ROM}$. Open $\mathrm{CD}$ file, copy the 'Optimal bucking system' folder to the hard drive. To run the optimal bucking system, double click the 'Optimal bucking system' folder from hard drive, and then click the optimalbucking.exe file.

\section{A.3 Data Entry}

To enter a new stem data, click 'Stems' under "Edit" from the main menu bar. A data entry dialog will pop out (Figure A.1). 


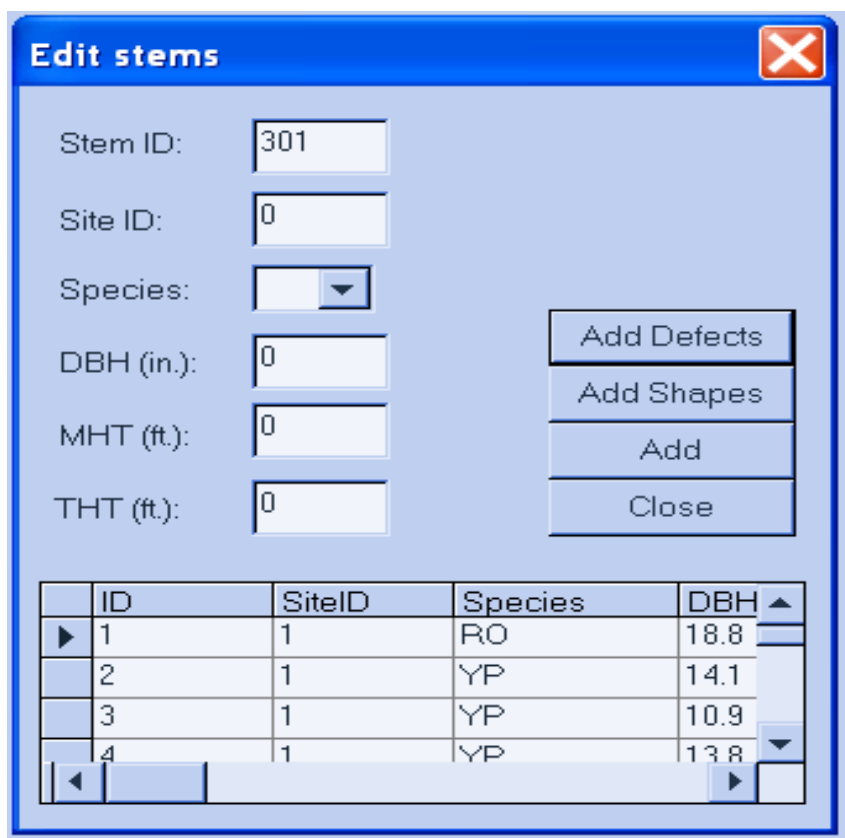

Figure A.1. Dialog box for editing stems.

To add a new stem enter stem ID, site ID, species, DBH, MHT and THT on the top part of the dialog box (Table A.2). Then click 'Add' button to add this stem into the database. The user can make changes to existing records using the bottom data grid in the dialog box.

Table A.2. Stem data description.

\begin{tabular}{lll}
\hline Item & Type & Description \\
\hline Stem ID & Integer & Stem number \\
Site ID & Integer & Site number, where stem measured \\
Species & Text & Species of entered stem, select from drop list box \\
DBH & Single & Diameter at breast height of stem \\
MHT & Single & Merchantable height of stem \\
THT & Single & Total height of stem \\
\hline
\end{tabular}

To add stem shape data, click 'Add Shapes" button, an "Edit shapes" dialog will pop out (Figure A.2). Stem ID will be the same as the stem ID used in the stem editing dialog box. Shape ID will be "1" and be automatically increased after each addition. Shape data include: Distance, Diameter, Sweep1, and Sweep2 (Table A.3). Click "Add” button, the shape data will be saved to the stem shape table. To make changes to existing 
records for stem shapes, following the same procedures as mentioned above for stem edition.

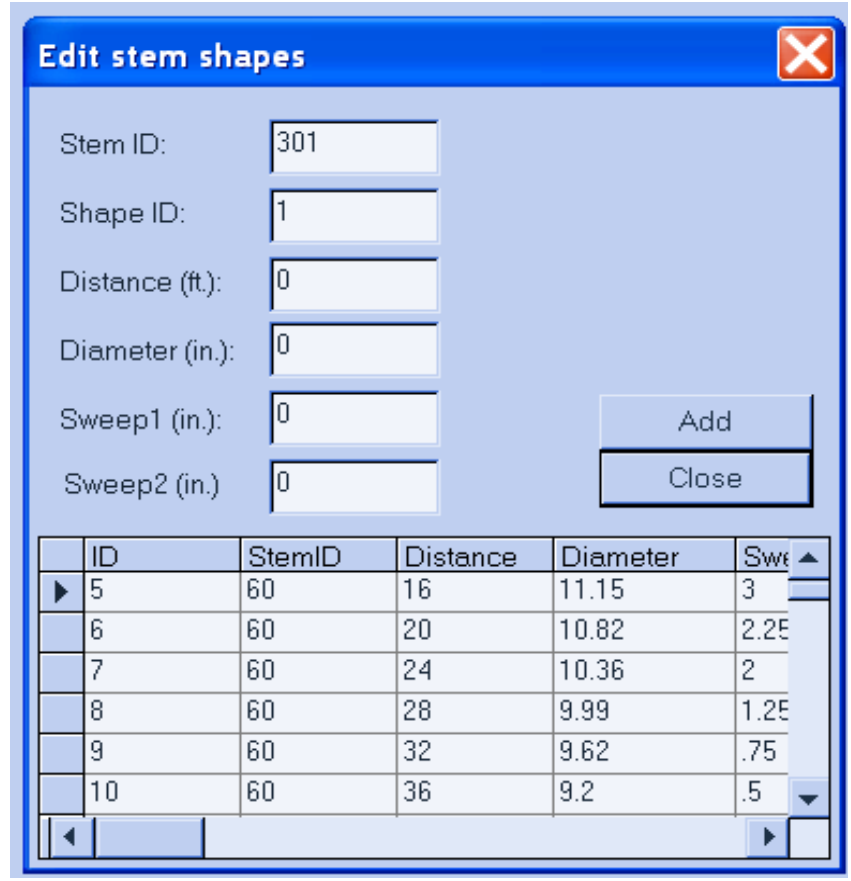

Figure A.2. Dialog box for editing stem shapes.

Table A.3. Shape data description.

\begin{tabular}{|c|c|c|}
\hline Item & Type & Description \\
\hline Stem ID & Integer & Automatically retrieved from stem editing dialog box \\
\hline Shape ID & Integer & Automatically increased from 1 \\
\hline Distance & Integer & $\begin{array}{l}\text { Distance of current position to the butt end of stem in } \\
\text { feet. }\end{array}$ \\
\hline Diameter & Single & Diameter at current position in inches \\
\hline Sweep1 & Single & $\begin{array}{l}\text { Horizontal distance of stem surface at current position } \\
\text { to horizontal reference level in inches }\end{array}$ \\
\hline Sweep2 & Single & $\begin{array}{l}\text { Vertical distance of stem surface at current position to } \\
\text { vertical reference level in inches }\end{array}$ \\
\hline
\end{tabular}

Similarly, the user can add the defects data for the stem. Click "Add Defects" button, in the dialog box (Figure A.3) enter Type, Distance, Length, Width, and Angle of defects (Table A.4). 


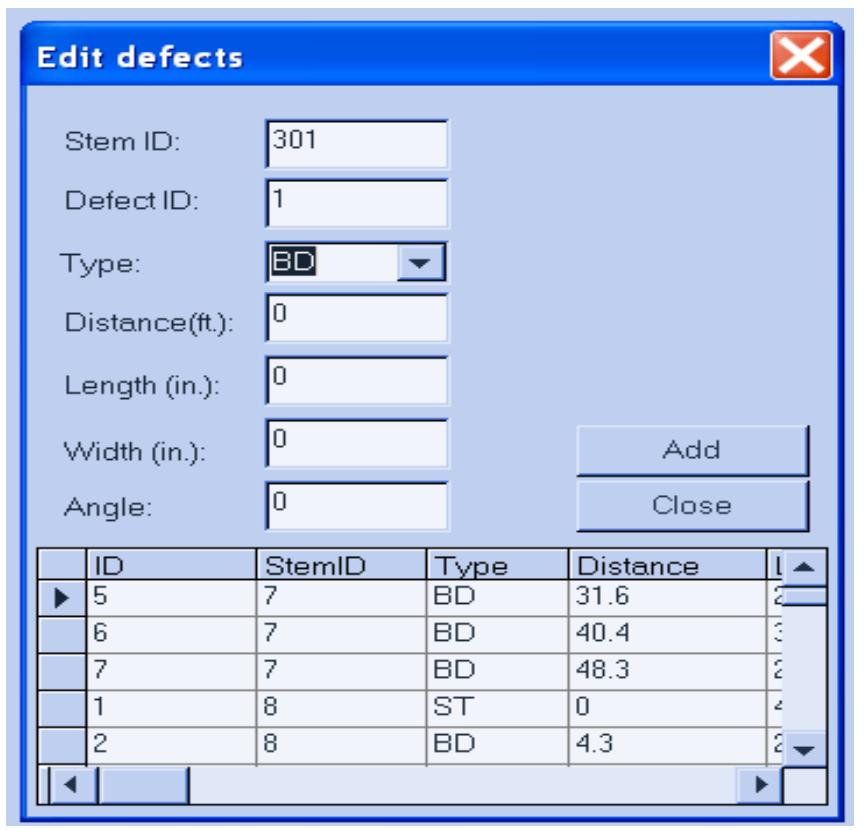

Figure A.3. Dialog box for editing stem defects.

Table A.4. Defect data description.

\begin{tabular}{lll}
\hline Item & Type & Description \\
\hline Stem ID & Integer & Automatically retrieved from stem editing dialog box \\
Defect ID & Integer & Automatically increased from 1 \\
Type & Text & Type of defect, select from the drop list box \\
Distance & single & Distance of defect to butt end of the stem in feet \\
Length & Single & Length of defect in inches \\
Width & Single & Maximum width of defect in inches \\
Angle & Integer & Angle of defect to top surface of the stem \\
\hline
\end{tabular}

To edit or add new log grades and prices, click "Edit" from the main menu bar.

Then click "Grades \& Prices", a grade editing dialog box will pop out (Figure A.4). First enter ID, Grade, Specie, Length, Diameter, Clearface, Deduction, Price (Table A.5). Then click "Add" button to save data back into the database. The user can make changes to existing record by using the datagrid. 


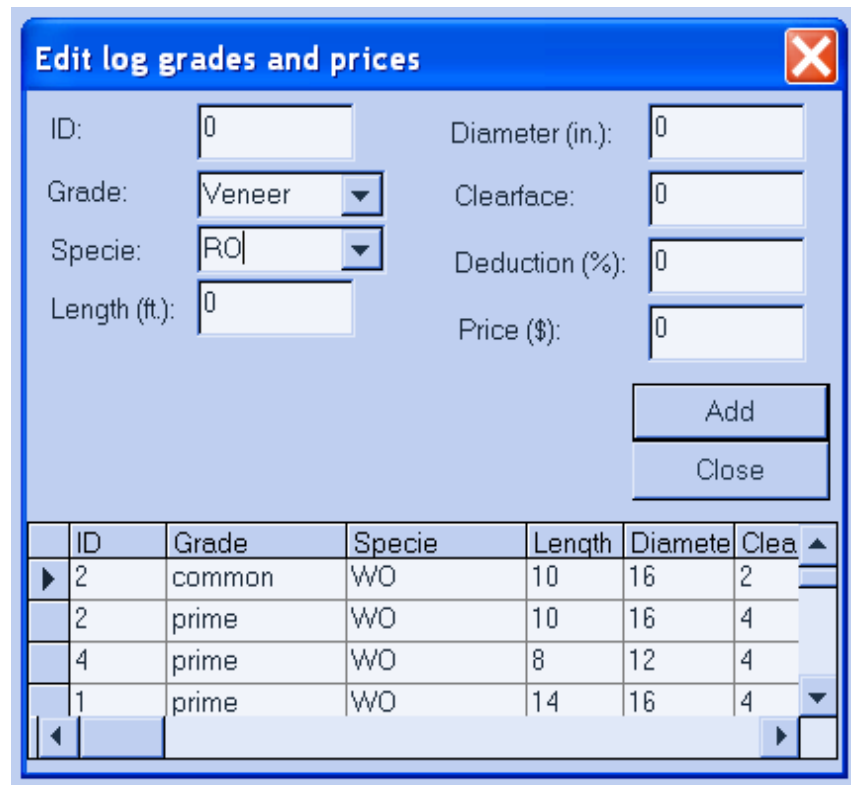

Figure A.4. Dialog box for editing log grades and prices.

Table A.5. Grade and price data description.

\begin{tabular}{lll}
\hline Item & Type & Description \\
\hline ID & Integer & Select from Prime, Veneer, Common, and below \\
Text & Common \\
Specie & Text & Select from drop list box \\
Length & Integer & Minimum length of log in feet \\
Diameter & Integer & Minimum diameter of log in inches \\
Clearface & Integer & Minimum number of clear faces, 0 to 4 \\
Deduction & Integer & Maximum percentage of volume deduction \\
Price & Integer & Dollars per thousand board feet \\
\hline
\end{tabular}

\section{A.4 Performing Bucking Simulation}

To start simulation, click "Bucking" from "Run" menu on the main menu bar.

A data tab control dialog box will pop out (Figure A.5). Select a stem under the "Stems" tab first. Then the user can view the defects, shapes and grades of the selected stem by clicking "Defects", "Shapes", or "Grades" tab. 


\begin{tabular}{|c|c|c|c|c|c|c|c|c|}
\hline \multicolumn{9}{|c|}{ Currently selected stem 1} \\
\hline Stems & ms $\mid$ Defects & \multicolumn{7}{|c|}{ | Shapes | Grades | } \\
\hline & ID & SitelD & Species & $\mathrm{DBH}$ & MHT & THT & 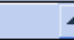 & $\boldsymbol{-}$ \\
\hline$\checkmark 1$ & 1 & 1 & $\mathrm{RO}$ & 18.8 & 40 & 89 & & \\
\hline & 2 & 1 & YP & 14.1 & 48 & 93 & & \\
\hline 3 & 3 & 1 & YP & 10.9 & 48 & 87 & & \\
\hline 4 & 4 & 1 & YP & 13.8 & 56 & 97 & & \\
\hline 5 & 5 & 1 & YP & 15.7 & 64 & 101 & & \\
\hline 6 & 6 & 1 & YP & 15.8 & 64 & 104 & & \\
\hline & 7 & 1 & YP & 18.7 & 56 & 110 & & \\
\hline & 8 & 1 & YP & 19.5 & 64 & 108 & & \\
\hline & 9 & 1 & YP & 15.2 & 56 & 109 & & \\
\hline & 10 & 1 & YP & 11.1 & 48 & 89 & & \\
\hline & 11 & 1 & RO & 13.5 & 48 & 87 & & \\
\hline & 12 & 1 & YP & 15.7 & 40 & 105 & & \\
\hline & 13 & 1 & $\mathrm{RO}$ & 14.7 & 32 & 87 & & \\
\hline & 14 & 1 & YP & 16.1 & 48 & 101 & & \\
\hline & 15 & 1 & $\mathrm{RO}$ & 15.4 & 40 & 89 & & \\
\hline & 16 & 1 & YP & 14.2 & 48 & 105 & & \\
\hline & 17 & 1 & YP & 13.8 & 48 & 97 & , & 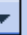 \\
\hline \multirow[t]{2}{*}{$|4|$} & & & & & & & 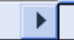 & \\
\hline & & & & & & ext & Close & \\
\hline
\end{tabular}

Figure A.5. Data tab control dialog box.

Click "Next" button to view the 3-D image of the selected stem (Figure A.6).

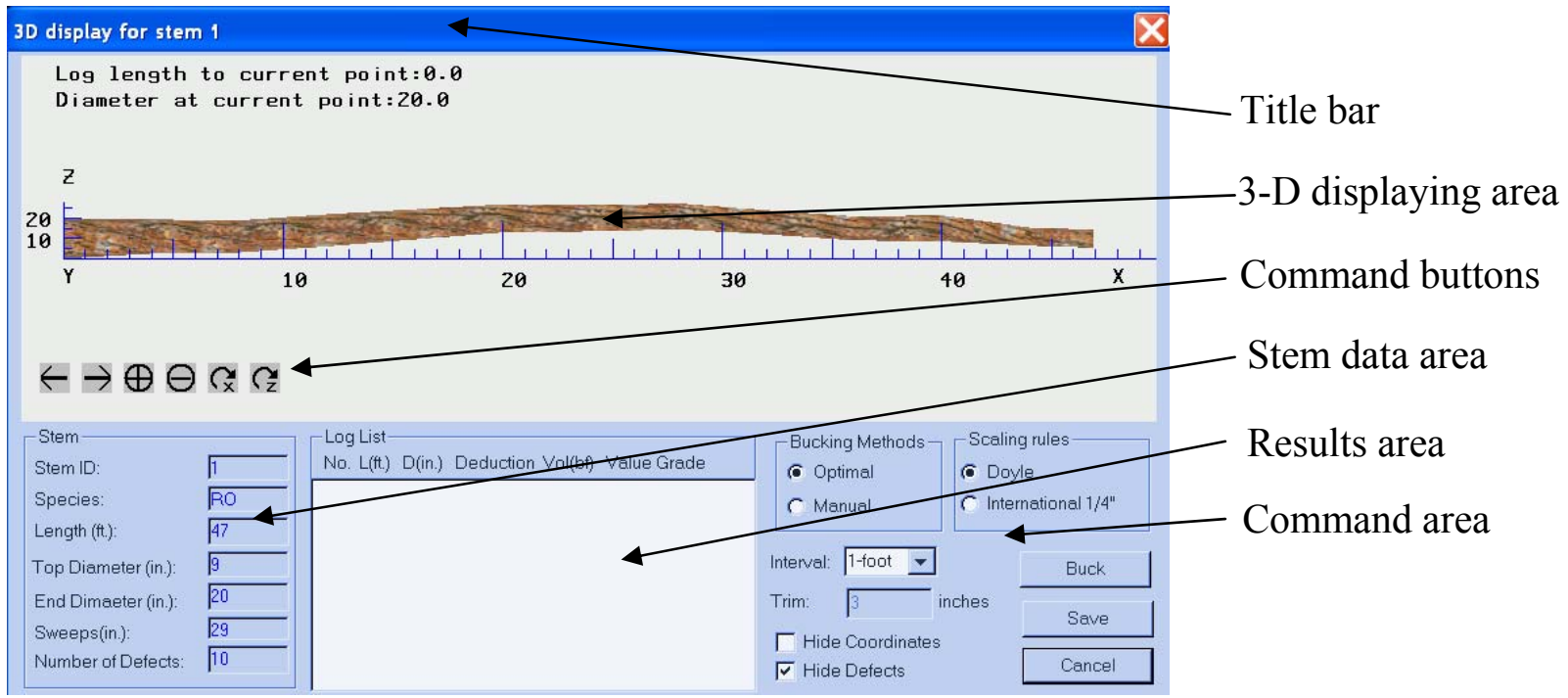

Figure A.6. A 3-D tree-stem for bucking simulation.

- Title bar: showing the title of the dialog;

- Command buttons: clicking to rotate, translate, zoom in or out a 3-D stem image.

- 3-D displaying area: displaying a 3-D stem image for a selected stem.

- Stem data area: showing the stem information of a selected stem. 
- Bucking results area: Listing bucking results of logs.

- Command area: Options for manual bucking, optimal bucking, Doyle or international $1 / 8$ " scaling rules, stage interval, showing or hiding coordinate and defects.

To run manual bucking, check the radio button of "Manual" in the command area, and then check the Doyle scaling rule. The user clicks the left or right arrow in the "command buttons" line to move the cutting point. Press "space key" on the keyboard to make a "cut". If satisfied with the bucking results, click "Save" button to save the results to log table, otherwise click "Cancel" button to start a new buck. When canceling a manual bucking, all cuts not saved will lost, and the original stem image will be redisplayed in the display area.

To perform computer optimal bucking, check "Optimal" from the "Bucking Methods". Then select a stage interval for network analysis algorithm and click the "Buck" button, the optimal system will yield the optimal solution. The optimal solution will be displayed in the results area, the 3-D images of bucked logs will be displayed as well. The user can either save the results or cancel it to perform a new bucking. 